\title{
Fourteen new species of Oecetis McLachlan, 1877 (Trichoptera: Leptoceridae) from the Neotropical region
}

\author{
Fabio B Quinteiro ${ }^{\text {Corresp., }}{ }^{1}$, Ralph W Holzenthal ${ }^{2}$ \\ ${ }^{1}$ Departamento de Biologia, Faculdade de Filosofia, Ciências e Letras de Ribeirão Preto, Universidade de São Paulo, Ribeirão Preto, São Paulo, Brazil \\ 2 Department of Entomology, University of Minnesota - Twin Cities Campus, Saint Paul, Minnesota, United States \\ Corresponding Author: Fabio B Quinteiro \\ Email address: fabiobquinteiro@gmail.com
}

Background. The caddisfly genus Oecetis currently contains 534 valid species. Its larval stages are found in freshwaters around the world. The adults can be distinguished from other Leptoceridae by the unbranched forewing $M$ vein and the exceptionally long maxillary palps. In the Neotropical region, 55 species of Oecetis have been recorded and most of them can be placed in one of the six species groups known from this biogeographical region: the avara-, falicia-, inconspicua-, punctata-, punctipennis-, and testacea-groups. More than $50 \%$ of the known diversity of Neotropical Oecetis has been described in the past 40 years. Here, we describe an additional 14 new species of Oecetis to further document the diversity of this genus in the Neotropical region.

Methods. The descriptions and illustrations presented here are based on male specimens. Specimens were collected with Malaise traps or ultraviolet light traps. They were preserved in alcohol or pinned as stated in material examined section. Specimens had their genitalia prepared in $10 \%$ lactic acid to better observe internal characters and illustrations were aided by the use of a microscope with drawing tube attached.

Results and Discussion. This study raises the number of species of Oecetis in the Neotropics from 55 to 69. Eight of the new species presented here could not be reliably placed in one of the known species groups (O. acuticlasper n. sp., O. flinti n. sp., O. carinata n. sp., O. cassicoleata n. sp., O. blahniki n. sp., O. gibbosa n. sp., O. licina n. sp., and $O$. pertica n. sp.). The others are placed in the punctata-group (O. bidigitata n. sp., O. quasipunctata n. sp.), testacea-group (O. plenuspinosa n. sp.), and falicia-group ( $O$. calori n. sp., O. hastapulla n. sp., O. machaera n. sp.). Most of the diagnostic characters rely on structures of the inferior appendages and phallic apparatus, and the shape of tergum $X$. 


\section{Fourteen new species of Oecetis McLachlan, 1877 (Trichoptera: Leptoceridae) from the Neotropical region}

Authors: Fabio B. Quinteiro ${ }^{1}$ and Ralph W. Holzenthal ${ }^{2}$

\section{Affiliation:}

${ }^{1}$ Departamento de Biologia, Faculdade de Filosofia, Ciências e Letras de Ribeirão Preto, Universidade de São Paulo, Ribeirão Preto, São Paulo, Brazil

${ }^{2}$ Department of Entomology, University of Minnesota - Twin Cities campus, Saint. Paul, Minnesota, United States.

Corresponding author: Fabio B. Quinteiro (fabiobquinteiro@gmail.com)

\section{Abstract}

Background. The caddisfly genus Oecetis currently contains 534 valid species. Its larval stages are found in freshwaters around the world. The adults can be distinguished from other Leptoceridae by the unbranched forewing $M$ vein and the exceptionally long maxillary palps. In the Neotropical region, 55 species of Oecetis have been recorded and most of them can be placed in one of the six species groups known from this biogeographical region: the avara-, falicia-, inconspicua-, punctata-, punctipennis-, and testacea-groups. More than 50\% of the known diversity of Neotropical Oecetis has been described in the past 40 years. Here, we describe an additional 14 new species of Oecetis to further document the diversity of this genus in the Neotropical region.

Methods. The descriptions and illustrations presented here are based on male specimens. Specimens were collected with Malaise traps or ultraviolet light traps. They were preserved in alcohol or pinned as stated in material examined section. Specimens had their genitalia prepared in $10 \%$ lactic acid to better observe internal characters and illustrations were aided by the use of a microscope with drawing tube attached.

Results and Discussion. This study raises the number of species of Oecetis in the Neotropics from 55 to 69. Eight of the new species presented here could not be reliably placed in one of the known species groups (O. acuticlasper n. sp., O. flinti n. sp., O. carinata n. sp., O. cassicoleata n. sp., O. blahniki n. sp., O. gibbosa n. sp., O. licina n. sp., and O. pertica n. sp.). The others are placed in the punctata-group (O. bidigitata n. sp., O. quasipunctata n. sp.), testacea-group ( $O$. plenuspinosa n. sp.), and falicia-group (O. calori n. sp., O. hastapulla n. sp., O. machaera n. 
sp.). Most of the diagnostic characters rely on structures of the inferior appendages and phallic apparatus, and the shape of tergum X.

\section{Introduction}

Oecetis McLachlan, 1877, is a genus within the caddisfly family Leptoceridae (Insecta: Trichoptera) with 534 valid species. The species in the genus are usually collected along rivers and lakes, where they tend to be very abundant (Schmid, 1998). The genitalia are characterized by having segment IX usually short, the preanal appendages somewhat prominent and ovoid, and the inferior appendages single-segmented (Schmid, 1998). The adults can be distinguished from other caddisflies by their unique wing venation, with an unbranched forewing $M$ vein (Quinteiro \& Calor, 2015), as well as their exceptionally long maxillary palps (Schmid, 1998). Their color ranges from pale yellow to dark brown and their size is from 6-12 $\mathrm{mm}$ (Henriques-Oliveira et al., 2014). The forewing often has characteristic brown spots.

Chen (unpublished data) provided a comprehensive treatment of Oecetis in his unpublished $\mathrm{PhD}$ dissertation. However, the genus has never undergone a thorough revision since Chen's work was never published. Nevertheless, many authors produced works on more restricted groups of species from around the world (e.g. Malicky, 2005; Rueda-Martín et al., 2011; Lee et al., 2012; Blahnik \& Holzenthal, 2014).

In the Neotropical region, specimens of Oecetis can be found in almost every freshwater environment, especially those with sandy substrate and slow running water. Fifty-five species of Oecetis have been recorded in the Neotropics (Holzenthal \& Calor, 2017) and most of them can be placed in one of six species group (Neboiss, 1989; Malicky, 2005): avara-, punctata-, falicia-, inconspicua-, punctipennis-, and testacea-group.

The avara-group has the shape and structure of the inferior appendages somewhat mitten-like as its most diagnostic aspect (Blahnik \& Holzenthal, 2014). Species from the avara-group are recorded from Canada to the north of South America (Blahnik \& Holzenthal, 2014).

The punctata-group species are restricted to the Neotropical region (Blahnik \& Holzenthal, 2014) and have the inferior appendages somewhat quadrate, often with apical processes bearing strong, thick setae. 
63 The falicia-group is also endemic to the Neotropics and can be diagnosed by the dorsolateral 64 processes on segment IX and the membranous tergum IX of the male (Chen, unpublished data).

65 The inconspicua-group is diagnosed by its phallic apparatus rounded and wide, with a pinched ventral projection and a helical phallic spine. This group was not properly addressed by Chen (unpublished data); even so it is often referred informally in the literature. Its species were treated as two groups by Chen: ochracea- and furva-group. However, they both share the very similar phallic apparatus shape and even an inferior appendage with rounded dorsal lobe and acuminate distal lobe apex. Representatives of this group can be found in all biogeographic areas except the Australasian and Oriental (Chen, 1993). In the Neotropics, the species recorded in this group are O. inconspicua (Walker), O. excisa Ulmer, O. pseudoinconspicua Bueno-Soria, O. amazonica (Banks) and O. pseudoamazonica, Rueda-Martin, Gibon, Molina.

The punctipennis-group can be diagnosed by the forewing $\mathrm{R}_{1+2}$ vein divided very close to the tip of the wing (Chen, unpublished data). This group seems to have a trans-Antartic distribution (South America, Australia) but the species in the Neotropical region have, as an additional diagnostic character, the phallic apparatus, short, bent ventrally, and with a horseshoe-shaped phallotremal sclerite. In the Neotropics, the included species in this group are: O. punctipennis (Ulmer), O. iguazu Flint and O. connata Flint.

The testacea-group is diagnosed as having a honeycomb microstructure covering abdominal tergum VIII and usually preceding terga, although their function is yet unknown (Malicky, 2005). Henriques-Oliveira et al. (2014) described $O$. iara, the only known species so far in the Neotropics with the honeycomb texture on abdominal terga. However, in the Nearctic region, there are species that share this morphological characteristic such as O. cinerascens (Hagen) and O. persimilis (Banks).

Significant contributions on the taxonomy of Oecetis in the Neotropical region were made in the last 40 years by several authors (Flint, 1974; Bueno-Soria, 1981; Rueda-Martín et al., 2011; Blahnik \& Holzenthal, 2014; Henriques-Oliveira et al., 2014; Quinteiro \& Calor, 2015). The species proposed by those authors account for more than $50 \%$ of the currently known species in the Neotropical region, but it is known that there is much more to do in caddisfly taxonomy in the Neotropics (Holzenthal \& Calor, 2017). Despite this increasing description of the Neotropical 
92 fauna, much of the region's biodiversity likely still remains unknown. There are species already 93 deposited and labeled in museums waiting to be described. This study advances the knowledge of Neotropical caddisfly diversity by describing fourteen new species of Oecetis based on morphological characteristics of the adult male.

\section{Material and Methods}

The specimens were primarily collected by use of ultraviolet fluorescent light bulbs placed in front of a white sheet, pan light traps (Calor \& Mariano, 2012), and Malaise traps. Those specimens collected on the white sheets are preserved dried and pinned. The remaining specimens were preserved in $80 \%$ ethyl alcohol.

For a more accurate study of some genital characters, genitalia were removed and cleared in $85 \%$ lactic acid (Blahnik et al., 2007) at $115^{\circ} \mathrm{C}$ for approximately 1 hour, washed with distilled water, and stored in $0.2 \mathrm{~mL}$ vials in approximately $50 \mu \mathrm{L}$ of glycerin in the vial bottom.

The specimens were examined and illustrated with the aid of a stereomicroscope with drawing tube attached. Pencil sketches were scanned with a flat-bed scanner, and placed in Adobe Illustrator CS5, where they were digitally inked. Species descriptions were made using the DELTA editor (Dallwitz, et al., 1999). Numbers in parentheses after "forewing length" in each description represent the number of specimens that integrate the type series and were used to calculate the average forewing length.

Terminology for wing venation and male morphology follows Quinteiro and Calor (2015). Type specimens are deposited at the University of Minnesota Insect Collection, St. Paul, Minnesota, USA (UMSP), National Museum of Natural History, Smithsonian Institution, Washington, DC, USA (NMNH), Muzeu de Zoologia da Universidade de São Paulo, São Paulo, Brazil (MZSP), Museo de Historia Natural Noel Kempff Mercado, Santa Cruz de la Sierra, Bolivia (UASC), Colección Entomológica de la Universidad de Antioquia, Medellín, Colombia (CEUA), and Museu de Zoologia da Universidade Federal da Bahia, Salvador, Brazil (UFBA), as indicated in the material examined. Distribution for each species is given by country and state, province, or department, summarized by the map presented at the end of the descriptions. The map was built 
120

121

122

123

124

125

126

127

128

129

130

131

132

133

134

135

136

137

138

139

140

141

142

143

144

145

146

147

148

149

150

using the website SimpleMappr (available at http://www.simplemappr.net). Species distributions are available as a supplemental data file $(. \mathrm{kml})$ and can be opened in Google Earth. For those specimens with collection labels that did not include geographical coordinates, approximate coordinates were used to plot into the map based on the other label data.

The electronic version of this article in Portable Document Format (PDF) will represent a published work according to the International Commission on Zoological Nomenclature (ICZN), and hence the new names contained in the electronic version are effectively published under that Code from the electronic edition alone. This published work and the nomenclatural acts it contains have been registered in ZooBank, the online registration system for the ICZN. The ZooBank LSIDs (Life Science Identifiers) can be resolved and the associated information viewed through any standard web browser by appending the LSID to the prefix http://zoobank.org/. The LSID for this publication is: urn:lsid:zoobank.org:pub:ED02CA58-B074-45A6-AAC7$48 F B 48 B 97 B A 8$. The online version of this work is archived and available from the following digital repositories: PeerJ, PubMed Central and CLOCKSS.

\section{Taxonomy}

Oecetis acuticlasper Quinteiro \& Holzenthal, n. sp. urn:lsid:zoobank.org:act:046E520D-07ED4892-BBDE-BE0654C5BE95

Fig. 1

Diagnosis. This species can be distinguished from all other Oecetis by the slender dorsal lobe of tergum $\mathrm{X}$, which is almost as long as the preanal appendage and laterally divided at its apex; and by the shape of the inferior appendage, with its enlarged, somewhat triangular ventral lobe, discrete, also triangular dorsal lobe, and a distal lobe, which is distinctly constricted and narrowed in the apical third of the appendage.

This species is morphologically similar to O. maspeluda Botosaneanu, 1977. Both of them have a dorsoventrally divided tergum X, short phallic apparatus, and a somewhat triangular inferior appendage. However, the dorsal lobe of tergum $\mathrm{X}$ in this new species is much shorter than in O. maspeluda and laterally divided at the apex. Also, the new species has the ventral margin of inferior appendage slightly concave in lateral view, giving an almost $90^{\circ}$ angle between the ventral and distal lobes, while in O. maspeluda this margin is smooth and almost 
151 straight. Additionally, the constriction present at the last third of the inferior appendage's length

152 in the new species is unique in Oecetis. This species does not have features to place it in any

153 known species group.

154

155

156

157

158

159

160

161

162

163

164

165

166

167

168

169

170

171

172

173

174

175

176

177

178

179

180

181

182

183

184
Description. Male: forewing length $6.5 \mathrm{~mm}(\mathrm{n}=1)$.

Head. Color yellowish brown (specimens in alcohol); maxillary palps pale yellow, 5segmented, palpomeres subequal, densely covered with setae; labial palps yellow, 3-segmented.

Thorax. Pterothorax yellowish brown; forewing yellow; dark bands over cord absent, dark spots absent (Fig. 1A); fork I petiolate, fork V rooted; sectoral crossvein $(s)$ not aligned with $r-m$ (Fig. 1A). Hind wing with forks I and V present (Fig. 1B). Legs yellowish brown, mid leg with longitudinal row of spines on tibia and tarsal segments. Tibial spur formula 0,2,2.

Abdomen. Segment IX annular, short, bearing pair of lateral processes, slender, straight, tapering posteriorly, shorter than phallic apparatus; acrotergite absent (Fig. 1C-D). Preanal appendage short, digitate, bearing apical setae (Figs. 1C-D). Tergum X, in lateral view, divided into dorsal and ventral lobes (Fig. 1C); dorsal lobe modified into single cylindrical structure, with apex slightly divided, longer than ventral lobe, and with short apical setae (Figs. 1C-D); ventral lobe divided medially, with V-shaped incision, broad basally, digitate apically (Figs. 1CD). Inferior appendage 1-segmented, setose; dorsal lobe acuminate, discrete (Figs. 1C, 1E); ventral lobe protruding, triangular, apex acute; distal lobe narrow, tapering posteriorly, apex acute, with distinct constriction at distal third (Figs. 1C, 1E); short, stout spine-like setae present on inner surface (Fig. 1E). Phallic apparatus bilaterally symmetrical, cylindrical, short, strongly curved ventrally, with globular endotheca (Figs. 1F-G). Phallic spine and phallotremal sclerite absent (Figs. 1F-G).

Distribution. Brazil (Minas Gerais, Rio de Janeiro).

Material examined. Holotype: (male): BRAZIL, Minas Gerais, Presidente Olegário, Faz. Gigante, Armadilha Luminosa, 18³1'S, 46¹8'W, 1000 m, 02-05.iv.2007, Amorim, Ribeiro, Capellari, Borkent (MZSP). Paratype: BRAZIL, Rio de Janeiro, Nova Friburgo, mun. water supply, 950 m, 24 April 1977, C.M. \& O.S. Flint Jr. - 1 male (NMNH; identified as Oecetis n. sp. E in loan to UMSP).

Etymology. From Latin acutus $=$ pointed, in reference to the pointed tip of the inferior appendage, or clasper.

Oecetis flinti Quinteiro \& Holzenthal, n. sp. urn:lsid:zoobank.org:act:E760A8EB-7908-427CAC19-D11291E15FE8

Fig. 2 
185

186

187

188

189

190

191

192

193

194

195

196

197

198

199

200

201

202

203

204

205

206

207

208

209

210

211

212

213

214

215

216

217

218

219

220

Diagnosis. This species can be diagnosed from other Oecetis by its enlarged tergum IX, ovoid preanal appendage, and by the inferior appendage, which has a basal constriction and lacks dorsal and ventral lobes.

Important adjunct characters, such as the presence of dark spots on the forewing and the position of the main forks, are easily observable. This new species is similar to O. pratti Denning, 1947 since both have tergum $\mathrm{X}$ divided dorsoventrally, with a deflexed dorsal lobe, and an inferior appendage without dorsal and ventral lobes. However, the inferior appendage of this new species has a distinct constriction at its base, while $O$. pratti has the inferior appendage uniformly wide along its entire length. Oecetis flinti n. sp. has its preanal appendage short and ovoid, somewhat lobulate in lateral view, while in $O$. pratti they are long and digitate. The most evident characteristics of this new species that differ from $O$. pratti are the presence of a phallic spine in the phallic apparatus and the elongate tergum IX, which is much longer than sternum IX. This species does not fit within one of the recognized species groups.

Description. Male: forewing length $4.5 \mathrm{~mm}(\mathrm{n}=1)$.

Head. Color yellowish brown (specimens in alcohol); maxillary palps pale yellow; labial palps pale yellow, 3-segmented.

Thorax. Pterothorax yellowish brown; forewing yellow; dark bands over cord present (Fig. 2A); dark spots on $\mathrm{M}-\mathrm{Cu}$ fork, on basis of $\mathrm{Rs}$, on basis of $\mathrm{Cu}_{1}$ and $\mathrm{Cu}_{2}$, on junction of anal veins (Fig. 2A); forks I and V rooted; sectoral crossvein ( $s$ ) not aligned with $r-m$ (Fig. 2A). Hind wing with forks I and V present (Fig. 2B). Legs pale yellow, mid leg with longitudinal row of spines on tibia and tarsal segments. Tibial spur formula 1,2,2; apical spur of fore tibia very small.

Abdomen. Segment IX uneven, tergum IX longer than sternum IX; acrotergite absent (Fig. 2C). Preanal appendage slightly wider than long (ovoid), bearing apical setae (Figs. 2C-D). Tergum X, in lateral view, not divided into dorsal and ventral lobes, undivided medially, composed of single elongated lobe, broad basally, tapering apically, apex acuminate (Figs. 2CD). Inferior appendage 1-segmented, setose, broad basally; ventral and dorsal lobes absent (Figs. $2 \mathrm{C}-\mathrm{E}$ ); distal lobe narrow, tapering posteriorly, apex acute, discrete constriction close to base, slightly bent inward (Figs. 2C-E); short stout spine-like setae absent (Figs. 2C-E). Phallic apparatus slightly bilaterally asymmetrical, curved downward, cylindrical, elongate, rounded on base, tapering apically, apex acute (Figs. 2F-G). Phallotremal sclerite absent (Figs. 2F-G).

Distribution. Brazil (Tocantins).

Material examined. Holotype (male): BRAZIL, Tocantins, Mateiros, P.E. Jalapão, Cachoeira da Formiga, 10²0'58’'S, 46²8'23.1'W, 461m, 17.x.2008, luz, Calor, Mariano, Mateus (MZSP). Paratypes: same data as holotype -2 males (UFBA).

Taxonomic comment: The available specimens had damaged wings so it was not possible to illustrate an entire wing. 
221 Etymology. The specific epithet honors our colleague Dr. Oliver S. Flint for his contributions to

222

223

224

225

226

227

228

229

230

231

232

233

234

235

236

237

238

239

240

241

242

243

244

245

246

247

248

249

250

251

252

253

254

255

256

caddisfly taxonomy and his extensive studies in the Neotropical region.

Oecetis carinata Quinteiro \& Holzenthal, n. sp. urn:lsid:zoobank.org:act:404BC99D-A18C4322-892F-E824DA3B66CF

Fig. 3

Diagnosis. This species can be differentiated from other Oecetis by its laterally deeply divided tergum X, forming two slender terete lobes, and its inferior appendage with the ventral lobe quadrate and greatly enlarged, and its distal lobe rounded and very short.

This new species is very similar to O. inflata Flint, 1974 since they both share a deeply divided tergum X, forming two slender and terete processes. Additionally, they resemble each other in that the preanal appendages are short and digitate, the phallic apparatus is short and strongly curved ventrally, and the forewing venation is almost identical. However, the new species has the ventral lobe of the inferior appendage quadrate and greatly enlarged in relation to the distal lobe. Oecetis inflata has the ventral lobe of the inferior appendage somewhat quadrate, but the ventral margin is very smooth and not as angled as in the new species. Additionally, the distal lobe of the inferior appendage in Oecetis carinata is reduced compared to O. inflata. This new species does not have characteristics that allow placement in a known species group.

Description. Male: forewing length $6.5 \mathrm{~mm}(\mathrm{n}=1)$.

Head. Color yellowish brown (specimens in alcohol); maxillary palps yellowish brown, 5-segmented, palpomeres subequal; labial palps pale yellow, 3-segmented.

Thorax. Pterothorax yellow; forewing yellowish brown; dark bands over cord absent (Fig. 3A); dark spots absent; forks I and V rooted (Fig. 3A); sectoral crossvein ( $s$ ) aligned with $r$ $m$ (Fig. 3A). Hind wing with forks I and V present (Fig. 3B). Legs yellowish brown, mid leg with longitudinal row of spines over distal half of femur, all along tibia and first tarsal segment. Tibial spur formula $0,2,2$.

Abdomen. Segment IX annular, short; acrotergite absent (Fig. 3C). Preanal appendage short, digitate, bearing apical setae (Figs. 3C-D). Tergum X, in lateral view, divided in dorsal and ventral lobes; dorsal lobe divided medially, forming two slender, terete lobes, apices acuminate; ventral lobe undivided, short, apex rounded in dorsal view and acute in lateral view (Figs. 3C-D). Inferior appendage 1-segmented, setose; dorsal lobe absent (Figs. 3C, 3E); ventral lobe quadrate, keeled, enlarged, margin angular (Figs. 3C, 3E); distal lobe a broad, smoothly rounded projection; short and stout spine-like setae absent (Figs. 3C, 3E). Phallic apparatus bilaterally symmetrical, cylindrical, short, strongly curved ventrally (Figs. 3F-G). Phallic spine and phallotremal sclerite absent (Figs. 3F-G).

Distribution. Brazil (Bahia, São Paulo). 
257 Material examined. Holotype (male): BRAZIL, São Paulo, São Carlos, Córrego Fazzari, 258 20.xii.2007, malaise trap (MZSP). Paratypes: BRAZIL, Bahia, Mucugê, Sempre Viva, Córrego 259 do Boiadeiro, 10.v.2015, malaise, Dias \& Campos - 2 males, 2 females (UFBA).

260 Etymology. From Latin carina $=$ keel, referring to the keel-like ventral lobe of the inferior 261 appendage in ventral view.

262

263

264

265

266

267

268

269

270

271

272

273

274

275

276

277

278

279

280

281

282

283

284

285

286

287

288

289

290

291

292

293

Oecetis cassicoleata Quinteiro \& Holzenthal, n. sp. urn:lsid:zoobank.org:act:140E12D6-B0224128-9AB9-BF148264378F

Fig. 4

Diagnosis. This species can be distinguished from the other species in Oecetis by its inferior appendage, which has the distal lobe curved, forming an obtuse angle along its length, and by the enlarged phallobase, with a lamellate process distally over the endotheca.

This new species has no similar species in the Neotropical region. Some species, such as O. testacea (Curtis, 1834) or O. cinerascens (Hagen, 1861), share an enlarged phallic apparatus, but both of them have phallic spines and a modified, reticulate tergum VIII, both characteristics not present in this species. Also, the inferior appendage of the new species is very distinct, having a rounded, slightly projected dorsal lobe, which becomes forward-pointing due to the concavity of the distal lobe, which forms an obtuse angle. Additionally, the presence of a flaplike projection on the dorsodistal margin of the phallobase is very conspicuous. This is another new species that cannot be placed in a named species group.

Description. Male: forewing length $5.5 \mathrm{~mm}(\mathrm{n}=1)$.

Head. Color yellowish brown (specimens in alcohol). Scape stout; pedicel short; maxillary palps pale yellow, 5-segmented; labial palps pale yellow, 3-segmented.

Thorax. Pterothorax yellowish brown; forewing yellow; dark bands over cord absent (Fig. 4A); dark spots on forks, junctions and end of veins; fork I rooted, fork V sessile; sectoral crossvein $(s)$ not aligned with $r-m$ (Fig. 4A). Hind wing with forks I and V present (Fig. 4B). Legs yellowish brown. Tibial spur formula 0,2,2.

Abdomen. Segment IX annular, short; acrotergite absent (Figs. 4C-D). Preanal appendage short, rounded, bearing apical setae (Figs. 4C-D). Tergum X, in lateral view not divided into dorsal and ventral lobes, composed of single elongate lobe, undivided medially, broad basally, tapering apically, apex acute (Figs. 4C-D). Inferior appendage 1-segmented, setose; in lateral view, dorsal lobe broad, rounded, projecting forward (Fig. 4C); ventral lobe absent (Figs. 4C-D); in lateral view, distal lobe narrow, cylindrical, bent posteriorly, forming a concavity ventrally, apex rounded (Fig. 4C); short, stout spine-like setae absent (Figs. 4C-D). Phallic apparatus slightly bilaterally asymmetrical, curved downward, cylindrical, elongate, broad basally, tapering distally, apex truncate, bearing flap-like projection distally on dorsal surface (Figs. 4E-F). Phallic spine and phallotremal sclerite absent (Figs. 4E-F). 
Distribution. Brazil (Bahia).

295

296

297

298

299

300

301

302

303

304

305

306

307

308

309

310

311

312

313

314

315

316

317

318

319

320

321

322

323

324

325

326

327

328

329

Material examined. Holotype (male): BRAZIL, Bahia, Barreiras, Rio de Janeiro, cach. Acaba

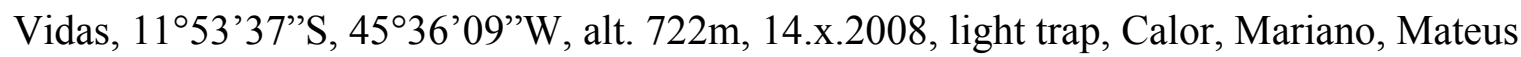
(MZSP).

Etymology. From Latin cassis $=$ cap and coleatus $=$ pertaining to the penis, referring to the hood-like projection on the dorsal surface of phallic apparatus covering the endotheca.

Oecetis bidigitata Quinteiro \& Holzenthal, n. sp. urn:lsid:zoobank.org:act:7A089FD8-F3F14339-898F-98DE402E3C81

Fig. 5

Diagnosis. This new species can be distinguished from the others in the punctata group by its stirrup-like phallotremal sclerite and by its inferior appendage, with a very short ventral lobe and two digitate projections bearing strong and thick setae on the distal lobe.

This species is very similar to $O$. knutsoni Flint, 1981 and O. quasipunctata n. sp. However, this species, differs from $O$. knutsoni and $O$. quasipunctata n. sp., by having a distinct stirrup-like phallotremal sclerite, not present in the other two species. Additionally, O. bidigitata n. sp. has only two digitate projections bearing strong and thick setae on the apex of the distal lobe of inferior appendage, while $O$. knutsoni and $O$. quasipunctata n. sp. have four projections.

Description. Male: forewing length 7.5-8.5 $\mathrm{mm}(\mathrm{n}=7)$.

Head. Color pale yellow (pinned specimens). Antennae 3 times length of forewing; scape stout, elongate; pedicel enlarged in width, subequal to other flagellomeres in length, shorter than scape. Maxillary palps yellowish brown, 5-segmented, palpomeres subequal in length and width, setose. Labial palps pale yellow, 3-segmented.

Thorax. Pterothorax yellowish brown; forewing yellow; dark bands over cord absent (Fig. 5A); dark spots on forks, junctions and end of veins; fork I rooted, fork V sessile (Fig. 5A); sectoral crossvein $(s)$ aligned with $r-m$ (Fig. 5A). Hind wing with forks I and V present (Fig. 5B). Legs yellow, mid leg with longitudinal row of spines on tibia and tarsal segments. Tibial spur formula $1,2,2$.

Abdomen. Segment IX annular, short; two acrotergites present dorsolaterally (Figs. 5CD). Preanal appendage very short, digitate, bearing apical setae (Figs. 5C-D). Tergum X, in lateral view not divided in dorsal and ventral lobes, divided medially by $\mathrm{V}$-shape incision, in dorsal view broad basally, acute apically (Figs. 5C-D). Inferior appendage 1-segmented, broad basally, setose; dorsal lobe absent (Figs. 5C, 5E); ventral lobe quadrate, short (Figs. 5C, 5E); distal lobe narrow, short, two digitate projections on top, inner process curved inward (Figs. 5C, 5E); two short, stout spine-like apical setae present (Figs. 5C, 5E). Phallic apparatus bilaterally symmetrical, cylindrical, elongate, membranous apically, curved ventrally (Figs. 5F-H); in 
330

331

332

333

334

335

336

337

338

339

340

341

342

343

344

345

346

347

348

349

350

351

352

353

354

355

356

357

358

359

360

361

362

363

caudal view, phallobase narrowing distally, somewhat U-shaped (Fig. 5G). Phallic spine absent (Figs. 5F-H). Phallotremal sclerite U-shapped, with V-shaped incision distally (Fig. 5H).

Distribution. Bolivia (La Paz).

Material examined. Holotype (male): BOLÍVIA, Dept. La Paz, San Buenaventura-Ixiamas rd., Arroyo Maije at Puente Maije, 14²0.908'S, 6740.530’W, 278 m, 14.vii.2003, Robertson and Blahnik (UASC, on loan to UMSP). Paratypes: same data as holotype - 1 female (UMSP); BOLÍVIA, Dept. La Paz, ANMI Madidi, Chalalan Ecolodge, Rio Tuichi at entrance to lodge \& trib., 14 25.017'S, 67 54.378'W, 300 m, 27.vii.2003, Robertson and Blahnik - 3 males (UMSP); same data except Raya Mayo river at Anta trail, 14²8.134'S, 6755.761'W, 264 m, 26.vii.2003, Robertson and Blahnik - 3 males (NMNH).

Etymology. From Latin prefix $b i=$ two and digitus $=$ finger, referring to the two digitate projections on apex of the inferior appendages.

Oecetis quasipunctata Quinteiro \& Holzenthal, n. sp. urn:lsid:zoobank.org:act:B7E84B92234B-46F1-BDF0-9D74D1CA9AB9

Fig. 6

Diagnosis. This new species can be distinguished from the others in the punctata group by its inferior appendage, with the ventral lobe very reduced and forming an acute angle with the distal lobe, and also by the nearly straight distal lobe.

This new species is very similar to O. knutsoni, O. bidigitata n. sp., and O. punctata (Navás, 1924) (Fig. 7). Oecetis bidigitata has only two digitate projections apically on the distal lobe of the inferior appendage, while O. knutsoni, O. punctata, and O. quasipunctata n. sp. have four projections. Oecetis punctata has a concave inner surface of the inferior appendage (Fig. 7E, best seen in ventral view), while $O$. knutsoni, O. bidigitata n. sp., and O. quasipunctata n. sp. have the inner surface straight (Fig. 6E). The main differences between $O$. knutsoni and this new species are in the inferior appendage. Oecetis knutsoni has an inferior appendage with a long ventral lobe forming a straight angle with the distal lobe, while this new species has a very reduced ventral lobe forming an acute angle with the distal lobe. Additionally, O. knutsoni has the apex of the distal lobe slightly bent posteriorly, while the new species has it nearly straight.

Description. Male: forewing length 9.1-10.3 mm ( $\mathrm{n}=21)$.

Head. Color yellowish brown (pinned specimens). Antennae 3 times length of forewing; scape stout, elongate; pedicel enlarged in width, subequal to other flagellomeres in length, shorter than scape. Maxillary palps yellow, 5-segmented, palpomeres subequal in length and width. Labial palps yellow, 3-segmented. 
Thorax. Pterothorax yellow; forewing yellow; dark bands over cord absent (Fig. 6A); dark spots on forks, junctions and end of veins; forks I and V rooted (Fig. 6A); sectoral crossvein $(s)$ aligned with $r-m$ (Fig. 6A). Hind wing with forks I and V present (Fig. 6B). Legs pale yellow, mid leg with longitudinal row of spines on tibia and tarsal segments. Tibial spur formula 1,2,2.

Abdomen. Segment IX annular, very short; two acrotergites present dorsolaterally (Fig. 6C). Preanal appendage short, digitate, bearing apical setae (Figs. 6C-D). Tergum X, in lateral view, not divided into dorsal and ventral lobes, composed of single elongate lobe, broad basally, divided mesally by shallow depression (Figs. 6C-D). Inferior appendage 1-segmented, broad basally, setose (Figs. 6C, 6E); dorsal lobe absent; ventral lobe quadrate, very short (Figs. 6C, $6 \mathrm{E}$ ); distal lobe narrow, straight, short, with 4 digitate projections on top, inner process curved inward; short and stout spine-like apical setae present (Figs. 6C, 6E). Phallic apparatus bilaterally symmetrical, curved downward, cylindrical, short (Figs. 6F-H); in caudal view, apex short, cylindrical, phallobase tapering distally, with slightly "pinched" tip (Fig. 6G). Phallic spine and phallotremal sclerite absent (Figs. 6F-H).

Distribution. Colombia (Cauca, Valle, Quindió).

Material examined. Holotype (male): COLOMBIA, Cauca, Municipio de Inzá, Quebrada San Andrés, $1 \mathrm{~km} \mathrm{~S}$ del centro de San Andrés de Pisimbalá, 02³4’36”N, 7602'11'W, $1730 \mathrm{~m}$, 20.xii.1997, Fdo. Muñoz-Q. et al. (CEUA, on loan to UMSP); Paratypes: same data as holotype - 14 males (UMSP); COLOMBIA, Cauca, Municipio de Inzá, 500 m W Restaurante "La Portada", San Andrés de Pisimbalá, 02³4'56”N, 7602’36”W, 1750 m, 21.xii.1997, Fdo. Muñoz-Q. et al. - 16 males (UMSP); Municipio de Belalcazar, Quebrada Tálaga, $14 \mathrm{~km}$ N Páez (Belalcazar), 0242’24”N, 7601'05’W, 1680 m, 22.xii.1997, Fdo. Muñoz-Q. et al. - 12 males (UMSP); Río Cabuyal Pescador, $\sim 20 \mathrm{~km} \mathrm{~N} \mathrm{Piendamó} \mathrm{(Carretera} \mathrm{Panamericana),} \mathrm{0248’N,}$ 76³2’W, 1400 m, 28.xii.1997, Fdo. Muñoz-Q. et al. - 4 males (CEUA, on loan to UMSP ); Valle, Municipio El Cerrito, Río Cerrito, 7.1km E Hacienda “El Paraíso", 0338'59”N, 7609'10"W, 1950 m, 03.xii.1997, Fdo. Muñoz-Q. et al. - 4 males, 2 females (UFBA); Municipio de Cali, Río Pichindé, Peñas Blancas, 24km SW Cali, 0325'06”N, 76³9'04”W, 2000 m, 18.xii.1997, Fdo. Muñoz-Q. et al. - 12 males, 2 females (UMSP); Quindió, Río Quindió, Retén “La Playa”, 2km NE Salento, 04³8'25”N, 75³3’24”W, 1890 m, 02.i.1998, Fdo. Muñoz-Q. et al. - 2 males, 2 females (NMNH).

Etymology. From Latin quasi = appearing as if, similar. This is a reference to the resemblance of this new species with Oecetis punctata (Navás, 1924), illustrated in Figure 7.

Oecetis calori Quinteiro \& Holzenthal, n. sp. urn:lsid:zoobank.org:act:58B08D3F-32E2-44089D62-24A46FAB2B5F

Fig. 8 
400

401

402

403

404

405

406

407

408

409

410

411

412

413

414

415

416

417

418

419

420

421

422

423

424

425

426

427

428

429

430

431

432

433

434

435

436

437

Diagnosis. This new species can be diagnosed from the others in the falicia group by its three phallic spines and by the inferior appendage with a small, discrete, quadrate basal projection with a truncate apex, and a triangular, protruding, and very angular ventral lobe.

This new species is similar to O. fibra Chen \& Morse in Quinteiro \& Calor, 2012 and to O. acarati Angrisano \& Sganga, 2009; all of them share a segment IX with slender, ventrally directed dorsolateral processes with no ramifications, and a terete, apically rounded distal lobe on the inferior appendage. However, none of the described species possess three spines in the phallic apparatus as in the new species. Additionally, the inferior appendage of O. fibra has a quadrate ventral lobe with smooth margins, while in $O$. acarati and the new species this lobe is triangular. Oecetis acarati has the ventral lobe of inferior appendage with a smooth margin and no dorsal lobe, while $O$. calori, n. sp. has a discrete quadrate dorsal lobe and a triangular flattened ventral lobe.

Description. Male: forewing length 7.3-7.6 $\mathrm{mm}(\mathrm{n}=3)$.

Head. Color yellowish brown (pinned specimens). Antennae 3 times length of forewing; scape stout, elongate; pedicel enlarged in width, subequal to other flagellomeres in length, shorter than scape. Maxillary palps yellow, 5-segmented. Labial palps yellow, 3-segmented.

Thorax. Pterothorax yellow; forewing yellowish brown; dark bands over cord absent (Fig. 8A); dark spots absent; forks I and V rooted (Fig. 8A); sectoral crossvein $(s)$ not aligned with $r-m$ (Fig. 8A). Hind wing with forks I and V present (Fig. 8B). Legs pale yellow, mid leg with longitudinal row of spines on tibia and tarsal segments. Tibial spur formula 1,2,2.

Abdomen. Segment IX annular, short, bearing pair of dorsolateral processes; processes slender, bent ventrad, cylindrical, tapering posteriorly, same length as phallic apparatus; acrotergite absent (Figs. 8C-D). Preanal appendage long, digitate, bearing apical setae (Figs. 8C-D). Tergum $\mathrm{X}$, in lateral view, divided into dorsal and ventral lobes; dorsal lobe modified into single cylindrical structure, apex digitate, same length as ventral lobe, with short apical setae (Figs. 8C-D); ventral lobe deeply divided laterally, forming two cylindrical lobules, apices rounded (Figs. 8C-D, black arrowheads). Inferior appendage 1-segmented, broad at base, setose; dorsal lobe in lateral view quadrate, discrete (Figs. 8C, 8E); ventral lobe, in lateral view, quadrate (Figs. 8C, 8E); distal lobe narrow, tapering posteriorly, apex rounded (Figs. 8C, 8E); short, stout spine-like setae present on inner surface (Fig. 8E). Phallic apparatus bilaterally symmetrical, curved downward, cylindrical, elongate, membranous apically (Figs. 8F-H); apex elongate, in caudal view (Fig. 8G). Three phallic spines present, curved downward (Fig. 8F-G). One phallotremal sclerite present, horseshoe-shaped, with discrete concavities on sides (Figs. $8 \mathrm{G})$.

Distribution. Brazil (Minas Gerais).

Material examined. Holotype (male): BRAZIL, Minas Gerais, Aldeia da Cachoeira das Pedras, 2006.824'S, 4401.412'W, 925 m, 28-29.ix.2000, Paprocki and Braga (MZSP).

Paratypes: same data as holotype -1 female (UMSP); Brazil, Minas Gerais, Estação 
438 Ecológica de Peti, Córrego Brucutu, 1952.995’S, 43²2.452’W, 29.ix.1998, Paprocki - 2 males, 4391 female (UMSP).

440 Etymology. The specific epithet honors our colleague Adolfo R. Calor for his contributions to caddisfly taxonomy and systematics, especially of the Brazilian fauna.

Oecetis hastapulla Quinteiro \& Holzenthal, n. sp. urn:lsid:zoobank.org:act:B43E4DCE-35794BDD-B803-B32151AB0327

445 Fig. 9

446

447

448

449

450

451

452

453

454

455

456

457

458

459

460

461

462

463

464

465

466

467

468

469

470

471

472

473

474

Diagnosis. This new species can be discriminated from the others in the falicia group by the very elongate dorsal lobe of tergum $\mathrm{X}$, with its slightly clavate apex, the divided apex of the inferior appendage, and by the elongate, asymmetrical, dorsolateral processes on segment IX.

This new species is very similar to $O$. prolongata Flint, 1981, since both of them have an elongate and terete dorsal lobe of tergum $\mathrm{X}$, an inferior appendage with the apex divided, and the dorsolateral processes of segment IX asymmetrical. However, this new species has the apex of dorsal lobe of tergum X clavate, while $O$. prolongata has it uniform in width along its entire length. Also, Oecetis hastapulla n. sp. has the dorsolateral processes of segment IX longer than those of $O$. prolongata and the process on the right side of the body is bent posteriorly, while those of $O$. prolongata are bent ventrally.

Description. Male: forewing length $6.5 \mathrm{~mm}(\mathrm{n}=2)$.

Head. Color yellowish brown (pinned specimens). Antennae 2.5 times length of forewing; scape stout, elongate; pedicel enlarged in width, subequal to other flagellomeres in length, shorter than scape. Maxillary palps yellow, 5-segmented, setose. Labial palps pale yellow, 3-segmented.

Thorax. Pterothorax yellowish brown; forewing yellow; dark bands over cord absent (Fig. 9A); dark spots absent (Fig. 9A); forks I and V rooted; sectoral crossvein ( $s$ ) not aligned with $r-m$ (Fig. 9A). Hind wing with forks I and V present (Fig. 9B). Legs yellow, mid leg with longitudinal row of spines on tibia and tarsal segments. Tibial spur formula $0,2,2$.

Abdomen. Segment IX annular, short, bearing pair of dorsolateral processes, slender, bent ventrad, cylindrical, tapering posteriorly, not bilaterally symmetrical, with dark tips, tip of right process bent 90 degrees distally, same length as phallic apparatus; acrotergite absent (Figs. 9C-D). Preanal appendage long, digitate, bearing apical setae (Figs. 9C-D). Tergum X, in lateral view, divided into dorsal and ventral lobes; dorsal lobe modified into single cylindrical structure, apex clavate, longer than ventral lobe, with short apical setae (Figs. 9C-D); ventral lobe deeply divided laterally, forming two cylindrical lobules, apex acuminate, tips dark (Figs. 9C-D). Inferior appendage 1-segmented, broad basally, setose (Fig. 9C, 9E); dorsal and ventral lobes absent (Fig. 9C); distal lobe narrow, tapering posteriorly, with V-shaped incision on apex (Fig. 9C, 9E); short, stout spine-like setae absent (Fig. 9C, 9E). Phallic apparatus bilaterally 
475

476

477

478

479

480

481

482

483

484

485

486

487

488

489

490

491

492

493

494

495

496

497

498

499

500

501

502

503

504

505

506

507

508

symmetrical, curved downward, cylindrical, elongate, membranous apically (Figs. 9F-H); apex elongate, in caudal view, phallobase tubular, endotheca cylindrical (Fig. 9G). Phallic spine and phallotremal sclerite absent (Figs. 9F-H).

Distribution. Costa Rica (Guanacaste, Limón).

Material examined. Holotype (male): COSTA RICA, Guanacaste, Parque Nacional Guanacaste, ca. $0.7 \mathrm{~km}$ N Est. Maritza, $10.96^{\circ} \mathrm{N}, 85.50^{\circ} \mathrm{W}, 550 \mathrm{~m}, 31$.viii.1990, Huisman and Quesada (UMSP); Paratype: COSTA RICA, Limón, Parque Nacional Braulio Carrillo, Quebrada González, $10.160^{\circ} \mathrm{N}, 83.939^{\circ} \mathrm{W}, 480$ m, 12-14.v.1990, Holzenthal and Blahnik - 1 male (UMSP).

Etymology. From Latin hasta $=$ spear, pullus $=$ dark-colored, blackish. This is a reference to the sclerotized tips of the dorsolateral processes and tergum $\mathrm{X}$.

Oecetis plenuspinosa Quinteiro \& Holzenthal, n. sp. urn:lsid:zoobank.org:act:9C9C4C21-B3F3454C-B5B3-A1D9709ABBCF

Fig. 10

Diagnosis. This new species can be placed close to those of the testacea-group as defined by (Malicky, 2005), due to the presence of reticulate modifications on abdominal segments V-VIII. Oecetis plenuspinosa can be distinguished from the other species of Oecetis by the shape of the inferior appendage, which lacks dorsal and ventral lobes, by the ventral lobe of tergum X, with two lateral, posterior pointing, digitate projections, and by the distinctly clavate dorsal lobe of tergum X. Additionally, the phallic apparatus has ten short spines, distributed symmetrically in two groups of five.

In the Neotropical region the only similar species, described to date, is $O$. iara HenriquesOliveira, et al., 2014. Oecetis plenuspinosa, n. sp. differs from O. iara due to its dorsal lobe of tergum $\mathrm{X}$, with clavate apex, while $O$. iara has the same structure broad basally, tapering toward an acute apex. Also, the new species has two digitate processes on the ventral margin of the ventral lobe of tergum $\mathrm{X}$ and a truncate apex on the inferior appendage, while $O$. iara does not have these processes on tergum $\mathrm{X}$ and has the inferior appendage with the apex digitate.

Description. Male: forewing length $5 \mathrm{~mm}(\mathrm{n}=1)$.

Head. Color pale yellow (pinned specimen). Antennae 3 times length of forewing; scape stout, elongate; pedicel enlarged in width, subequal to other flagellomeres in length, shorter than scape. Maxillary palps yellow, 5-segmented, setose. Labial palps pale yellow, 3-segmented.

Thorax. Pterothorax yellowish brown; forewing yellow; dark bands over cord absent; dark spots absent on wing; forks I and V rooted; sectoral crossvein $(s)$ not aligned with $r$ - $m$. Hind 
509

510

511

512

513

514

515

516

517

518

519

520

521

522

523

524

525

526

527

528

529

530

531

532

533

534

535

536

537

538

539

540

541

542

wing with forks I and V present. Legs yellowish brown, mid leg with longitudinal row of spines on tibia and tarsal segments. Tibial spur formula 1,2,2.

Abdomen. Segments V, VI, VII and VIII with honeycomb texture on terga (Figs. 10AC), segment VIII with honeycomb cells smaller than others (Fig. 10C); segment IX annular short (Figs. 10D-E). Preanal appendage digitate, bearing apical setae (Figs. 10D-E). Tergum X, in lateral view, divided into dorsal and ventral lobes; dorsal lobe elongate, cylindrical, apex distinctly clavate (Figs. 10D-E); ventral lobe divided into two digitate sclerotized processes, slender, curved slightly upward, rounded tip (Figs. 10D-E). Inferior appendage 1-segmented, setose (Figs. 10D, 10F); dorsal lobe absent (Figs. 10D, 10F); ventral lobe rounded (Figs. 10D, 10F); distal lobe narrow, cylindrical, distal half enlarged, apex truncate; short and stout spinelike setae absent (Figs. 10D, 10F). Phallic apparatus bilaterally symmetrical, curved downward, cylindrical, distal half enlarged, apex truncate, pair of short processes dorsally, both slender, acuminate (Fig. 10G), ten phallic spines present, small, sickle shaped, simetrically distributed in two groups of five (Fig. 10G, one side represented); in caudal view, with apex short, cylindrical, endotheca enlarged, bilobate laterally. Phallotremal sclerite present, horseshoe-shaped.

Distribution. Costa Rica (Limón).

Material examined. Holotype (male): COSTA RICA, Limón, E.A.R.T.H., forest reserve arroyo, 7.5 km (air) NW Pocora, 10¹3'48"N, 083³3'36"W, 10, 4-5.ii.1992, Holzenthal, R.W., Muñoz, F., Kjer, K.M. (UMSP).

Etymology. From Latin plenus $=$ full, plenty, spinosus $=$ thorny. This is a reference to the many small spines present in the phallic apparatus.

Oecetis machaera Quinteiro \& Holzenthal, n. sp. urn:lsid:zoobank.org:act:ED8452F1-64C24432-8B55-CCCAD8E58DC1

Fig. 11

Diagnosis. This species is distinguished from the others in the falicia group by its bilobate inferior appendage, with its ventral lobe elongate, cylindrical, and apically acute.

Oecetis machaera, n. sp. is similar to O. prolongata Flint, 1981 due to the short, slightly ventrally bent, short dorsolateral process on segment IX. However, O. prolongata has the ventral lobe of the inferior appendage absent. Oecetis machaera, n. sp. has the ventral lobe distinctly projected, cylindrical, and with an acute apex. Additionally, the phallic apparatus of $O$. prolongata is very long and strongly bent ventrally, while the phallic apparatus of the new species is short and almost straight.

Description. Male: forewing length $4.8 \mathrm{~mm}(\mathrm{n}=1)$. 
543

544

545

546

547

548

549

550

551

552

553

554

555

556

557

558

559

560

561

562

563

564

565

566

567

568

569

570

571

572

573

574

575

576

577

578

Head. Color yellowish brown (pinned specimen). Antennae 3.5 times length of forewing; scape stout, elongate; pedicel enlarged in width, subequal to other flagellomeres in length, shorter than scape. Maxillary palps yellowish brown, 5-segmented, setose.

Thorax. Pterothorax yellowish brown; forewing yellowish brown; dark bands over cord absent; dark spots absent; forks I and V rooted; sectoral crossvein $(s)$ not aligned with $r-m$. Hind wing with forks I and $\mathrm{V}$ present. Legs yellowish brown, mid leg with longitudinal row of spines on tibia and tarsal segments. Tibial spur formula 0,2,2.

Abdomen. Segment IX annular, short, bearing pair of dorsolateral processes, each thick, straight, apex slightly bent ventrad, flattened on basis, tapering posteriorly, shorter than phallic apparatus (Fig. 11A). Preanal appendage long, digitate, bearing apical setae (Figs. 11A-B). Tergum X, in lateral view, divided into dorsal and ventral lobes (Fig.11A); dorsal lobe modified into single cylindrical structure, apex digitate, shorter than ventral lobe, with short apical setae (Figs. 11A-B); ventral lobe divided medially by V-shape incision, broad basally, acute apically in dorsal view (Figs. 11A-B). Inferior appendage 1-segmented, setose (Figs. 11A, 11C); dorsal lobe absent (Fig. 11A); ventral lobe elongate, slightly shorter than distal lobe, apex acute (Figs. 11A, 11C); distal lobe narrow, tapering posteriorly, apex rounded in lateral view (Figs. 11A, 11C); short, stout spine-like setae absent (Figs. 11A, 11C). Phallic apparatus bilaterally symmetrical, curved downward, cylindrical, elongate, membranous apically (Fig. 11D); in caudal view, apex elongate, endotheca slightly enlarge in width apically; one projection on left side, acute, sclerotized (Fig. 11D). Phallic spine absent (Fig. 11D). Phallotremal sclerite horseshoe-shaped (Fig. 11D).

\section{Distribution. Brazil (Amazonas).}

Material examined. Holotype (male): BRAZIL, Amazonas, Am. 010, km 246, $20 \mathrm{~km} \mathrm{~W}$ Itacoatiara, 12-15.vii.1979, J. Arias et al. (NMNH, loan to UMSP).

Etymology. From Latin machaera = bent sword from ancient Greece, dirk, dagger. This specific epithet refers to the shape of the dorsolateral processes on segment IX in dorsal view, resembling the bent blade of some swords.

Oecetis blahniki Quinteiro \& Holzenthal, n. sp. urn:lsid:zoobank.org:act:9B6B3CF0-067A4C51-B1CB-FD3CC15A08EF

Fig. 12

Diagnosis. This species can be distinguished from other Oecetis by a combination of characters. It has tergum $\mathrm{X}$ divided dorsoventrally, segment IX with two lateral rounded processes, projecting between the dorsal and ventral lobes of tergum $X$, the endotheca bilobed, and the inferior appendage with the ventral margin of the distal lobe angular, and a ventral lobe that is projecting and cylindrical, with a rounded apex. 
This new species is similar to O. gibbosa, n. sp., O. traini Rueda-Martín, Gibon \& Molina, 2011, and $O$. rafaeli Flint, 1991 due to the presence of a distinct lateral process on segment IX and its short phallic apparatus. However, in O. traini and O. rafaeli the lateral processes are slender with acute apices, while in $O$. blahniki, n. sp. and O. gibbosa, n. sp. the apices are rounded, uniformly wide along their lengths, and project between the dorsal and ventral lobes of tergum $\mathrm{X}$. The diagnostic difference between the two new species relies especially on the shape of the inferior appendage. Oecetis blahniki, n. sp. has the ventral margin of the distal lobe strongly angular and a projecting, cylindrical ventral lobe, while $O$. gibbosa, n. sp. does not have a ventral lobe and its dorsal and distal lobes are terete and elongate. Additionally, O. blahniki, n. sp has the endotheca bilobed, while in $O$. gibbosa, n. sp. it is single lobed. This species does not have features to place it in any known species group.

Description. Male: forewing length $6.5 \mathrm{~mm}(\mathrm{n}=1)$.

Head. Color yellowish brown (pinned specimen). Scape stout, elongate; pedicel enlarged in width, subequal to other flagellomeres in length, shorter than scape. Maxillary palps yellowish brown, 5-segmented, setose. Labial palps yellow, 3-segmented.

Thorax. Pterothorax yellowish brown; forewing brown; dark bands over cord absent; dark spots absent; forks I and V rooted; sectoral crossvein $(s)$ not aligned with $r-m$. Hind wing with forks I and V present. Legs yellowish brown, mid leg with longitudinal row of spines on tibia and tarsal segments. Tibial spur formula 0,2,2.

Abdomen. Segment IX annular, short, bearing pair of lateral processes, thick, cylindrical, slightly sinuous, tapering posteriorly, apex rounded, shorter than phallic apparatus (Figs. 12AB). Preanal appendage short, rounded, apex somewhat pointing in dorsal view, bearing apical setae (Figs. 12A-B). Tergum X, in lateral view, divided in dorsal and ventral lobes (Figs. 12A$\mathrm{B}$ ); dorsal lobe modified into single cylindrical structure, apex acuminate, shorter than ventral lobe, with short apical setae (Figs. 12A-B); ventral lobe divided laterally by V-shaped incision, broad basally, digitate apically (Figs. 12A-B). Inferior appendage 1-segmented, setose (Figs. 12A, 12C); dorsal lobe absent (Fig. 12A); ventral lobe cylindrical, acuminate apex (Figs. 12A, $12 \mathrm{C}$ ); distal lobe narrow, tapering posteriorly, apex acute, angular projection ventrally on mid region, apex acute (Figs. 12A, 12C); short, stout spine-like setae absent (Figs. 12A, 12C). Phallic apparatus bilaterally symmetrical, cylindrical, short, slightly curved ventrally (Fig. 12D); in caudal view, apex elongate. Endotheca longer than phallobase, bilobate (Fig. 12D). Two phallic spines present, straight. Phallotremal sclerite horseshoe-shaped.

Distribution. Brazil (Amazonas).

Material examined. Holotype (male): BRAZIL, Amazonas, Am. 010, km 246, 20km W Itacoatiara, 12-15.vii.1979, J. Arias et al. (NMNH loan to UMSP).

Etymology. This specific epithet honors our colleague Roger J. Blahnik for his contributions to caddisfly taxonomy and systematics. 
617 Oecetis gibbosa Quinteiro \& Holzenthal, n. sp. urn:lsid:zoobank.org:act:3118C6F6-3776-4624-

618 B2E2-9615553CF62A

619 Fig. 13

620 Diagnosis. This species can be differentiated from the other Oecetis by its dorsoventrally divided 621 tergum X, the presence of two lateral processes on segment IX with their apices truncate and 622 projecting between the lobes of tergum $\mathrm{X}$, and by the inferior appendage with an elongate, 623 cylindrical distal lobe and dorsal lobe that is slightly clavate apically and with a rounded, mesal 624 lobe at midlength.

625 This new species is similar to Oecetis traini Rueda-Martín, Gibon \& Molina, $2011, O$. 626 rafaeli Flint, 1991, and O. blahniki, n. sp. due to segment IX bearing a lateral process and also 627 the short phallic apparatus. However, the lateral processes on segment IX in $O$. traini and $O$. 628 rafaeli are slender, with acute apices, while the new species has them somewhat quadrate. 629 Oecetis gibbosa, n. sp. differs from O. blahniki, n. sp. in the lateral projections of segment IX, 630 which have their apices truncate in $O$. gibbosa, n. sp., while O. blahniki, n. sp. has them rounded. 631 Also, Oecetis gibbosa, n. sp. has the inferior appendage with elongate dorsal and distal lobes, 632 and with an inner lobe on the dorsal lobe, while Oecetis blahniki, n. sp. does not have a 633 developed dorsal lobe, and the distal lobe has a very angular ventral margin. Like some of the 634 previous species presented here, this new species does not present any distinct characteristic that 635 would allow us to place it in a species group.

636 Description. Male: forewing length $5 \mathrm{~mm}(\mathrm{n}=1)$.

637 Head. Color yellowish brown (pinned specimen). Scape stout, elongate; pedicel enlarged 638 in width, subequal to other flagellomeres in length, shorter than scape. Maxillary palps yellowish 639 brown, 5-segmented, setose. Labial palps yellow, 3-segmented.

640 Thorax. Pterothorax yellowish brown; forewing brown; dark bands over cord absent; 641 dark spots absent; forks I and V sessile; sectoral crossvein $(s)$ not aligned with $r$ - $m$. Hind wing 642 with forks I and V present. Legs yellowish brown. Tibial spur formula 0,2,2.

Abdomen. Segment IX annular, short (Figs. 13A-B). Preanal appendage long, digitate, bearing apical setae (Figs. 13A-B). Tergum X, in lateral view, divided into dorsal and ventral lobes (Figs. 13A-B); dorsal lobe modified into single cylindrical structure, apex digitate, nearly same length as ventral lobe, with short apical setae (Figs. 13A-B); ventral lobe undivided laterally, trapezoidal, smooth edges, apex truncate (Figs. 13A-B). Inferior appendage 1segmented, broad basally, setose (Figs. 13A, 13C); dorsal lobe long, slender, apex clavate, with distinct rounded projection at mid region on mesal surface (Figs. 13A, 13A'), setae on inner surface of tip and mid region projection; ventral lobe absent (Figs. 13A, 13C); distal lobe narrow, 651 tapering posteriorly, apex rounded, setose, forming $90^{\circ}$ angle with dorsal lobe (Figs. 13A, 13C). Phallic apparatus bilaterally symmetrical, curved downward, cylindrical, elongate, membranous 
653 apically (Fig. 13D). One phallic spine present, slightly bent dorsally (Fig. 13D). Phallotremal 654 sclerite absent (Fig. 13D).

655 Distribution. Brazil (Amazonas).

656 Material examined. Holotype (male): BRAZIL, Amazonas, Am. 010, km 229, 38km W 657 Itacoatiara, 29.i.1975, O.S. Flint Jr. (NMNH loan to UMSP).

658 Etymology. From Latin gibbosus = very humped. This species name is a reference to the 659 projection observed at the mid region of the inferior appendage in caudal view.

660

661

662

Oecetis pertica n. sp. Quinteiro \& Holzenthal, n. sp. urn:lsid:zoobank.org:act:3DA312EC-F046-

663 4F36-8FD6-D61FF1D9E4AD

Fig. 14

664

665

666

667

668

669

670

671

672

673

674

675

676

677

678

679

680

681

682

683

684

685

686

687
Diagnosis. Oecetis pertica $\mathrm{n}$. sp. can be distinguished from the other Oecetis by the long and cylindrical dorsal lobe of tergum $\mathrm{X}$, together with the somewhat quadrate dorsal lobe of the inferior appendage with its apex truncate, and the presence of a protruding ventral lobe on the inferior appendage with a very angular margin and acute apex in lateral view. Also, the very conspicuous phallic spines are divided into two groups in different regions of the phallic apparatus. Finally, the quadrate lateral lobe on segment IX of this species is unique in Oecetis.

This species has the inferior appendage similar to O. doesburgi (Flint, 1974), since both have a $\mathrm{C}$-shaped incision between dorsal and distal lobes, and a dorsal lobe that is broad at its base, with its apex projecting distally. The new species has the dorsal lobe of inferior appendage with distinct truncate apex, whereas $O$. doesburgi presents it rounded. Also, O. doesburgi has the distal lobe enlarged apically, while $O$. pertica n. sp. has it narrow. The long dorsal lobe of tergum $\mathrm{X}$ and the mesally divided ventral lobe of tergum $\mathrm{X}$ of this new species are similar to $O$. prolongata Flint, 1981, but $O$. pertica $\mathrm{n}$. sp. does not have the dorsolateral processes on segment IX that are diagnostic of the falicia-group and present in O. prolongata. Finally, O. rafaeli Flint, 1991, and O. blahniki n. sp. also have a pair of lateral processes on segment IX, as well as $O$. pertica $\mathrm{n}$. sp., but neither of them has the lateral process quadrate, as in the new species. This new species does not have diagnostic characters that allow us to place it in a known species group.

Description. Male: forewing length $4.5 \mathrm{~mm}(\mathrm{n}=1)$.

Head. Color yellowish brown (pinned specimen). Scape stout, elongate; pedicel enlarged in width, subequal to other flagellomeres in length, shorter than scape. Maxillary palps yellowish brown, 5-segmented, setose. Labial palps yellow, 3-segmented.

Thorax. Pterothorax yellowish brown; forewing yellowish; small patches of dark setae present at junction of most veins, with patches of white setae adjacent to these; forks I and $\mathrm{V}$ 
688

689

690

691

692

693

694

695

696

697

698

699

700

701

702

703

704

705

706

707

708

709

710

711

712

713

714

715

716

717

718

719

720

721

722

723

sessile; sectoral crossvein $(s)$ not aligned with $r-m$. Hind wing with forks I and V present. Legs yellowish brown. Tibial spur formula 0,2,2.

Abdomen. Segment IX uneven dorsoventrally, with anterior margin projecting midlaterally, tergum IX noticeably shorter than sternum IX, segment bearing pair of broad, slightly quadrate lateral processes from the posterior margin, projecting underneath ventral lobe of tergum X; acrotergite absent (Figs. 14A-B). Preanal appendage long, digitate, bearing apical setae (Figs. 14A-B). Tergum X, in lateral view, divided into dorsal and ventral lobes (Figs. 14A$\mathrm{B}$ ); dorsal lobe modified into single cylindrical structure, apex slightly clavate, nearly same length as ventral lobe, with short apical setae (Figs. 14A-B); ventral lobe divided medially by Vshape incision, broad basally, apex acute (Fig. 14B). Inferior appendage 1-segmented, broad basally, setose (Figs. 14A, 14C); dorsal lobe slightly quadrate, projecting distally, apex truncate (Fig. 14A); ventral lobe slightly protruding basally, keeled, apex acute and margin very angular in lateral view (Fig. 14A), and broadly rounded in ventral view (Fig. 14C); distal lobe broad, tapering distally, slightly bent dorsad, apex rounded, forming with dorsal lobe shallow C-shaped incision; short and stout spine-like setae absent (Figs. 14A, 14C). Phallic apparatus bilaterally symmetrical, curved ventrally, tubular, elongate, membranous apically, constricted at mid portion, enlarged distally (Fig. 14D). Endotheca with approximately 12 short, straight, phallic spines, 5-7 at mid region, 5-7 at apex (exact number difficult to discern, endothecal membranes not everted on specimens examined) (Fig. 14D). Phallotremal sclerite absent (Fig. 14D).

Distribution. Brazil (Amazonas).

Material examined. Holotype (male): BRAZIL, Amazonas, Am. 010, km 229, 38 km W Itacoatiara, 29.i.1975, O.S. Flint Jr. (NMNH).

Etymology. From Latin pertica $=$ long pole. This species name refers to the long dorsal lobe of tergum X.

Oecetis licina n. sp. Quinteiro \& Holzenthal, n. sp. urn:lsid:zoobank.org:act:9BFC14F7-FCD14FF3-AA38-F62B52439CCD

Fig. 15

Diagnosis. This species does not have characters that allow us to place it in a diagnosed species group. However, it can be distinguished from the other Oecetis by the enlarged dorsal lobe of tergum $\mathrm{X}$, the triangular lateral process of segment IX, and the distinctly curved inferior appendage.

Oecetis licina n. sp. is similar to O. gibbosa n. sp., since they both share a segment IX lateral process protruding underneath tergum $\mathrm{X}$, as well as a cylindrical dorsal lobe of tergum $\mathrm{X}$ and a phallic apparatus that is cylindrical, slightly curved ventrally and bearing one phallic spine. Oecetis licina n. sp. is also similar to O. blahniki n. sp. based on the broad, mesally curved distal 
724 lobe of the inferior appendage and the rounded preanal appendage. However, O. licina n. sp. and

725

726

727

728

729

730

731

732

733

734

735

736

737

738

739

740

741

742

743

744

745

746

747

748

749

750

751

752

753

754

755

756

757

758

759

760

761

O. gibbosa n. sp. differ greatly in the inferior appendage shape. Oecetis gibbosa n. sp. has the dorsal lobe of inferior appendage terete, with apical and mesal inner projections. Oecetis licina $\mathrm{n}$. sp. has the dorsal lobe of inferior appendage discreetly projected and rounded. The distal lobe of the inferior appendage in $O$. licina $\mathrm{n}$. sp. is conspicuously enlarged compared to the terete distal lobe of inferior appendage in $O$. gibbosa n. sp. Also, the phallic apparatus in O. licina n. sp. is disproportionally large compared to the remainder of the genitalia. Compared to O. blahniki, n. sp., O. licina n. sp. has the ventral lobe of inferior appendage absent, whereas O. blahniki n. sp. has it cylindrical, with acuminate apex. Also, the lateral processes on segment IX of $O$. licina n. sp. are broad at base and triangular, with acute apex, while $O$. blahnik n. sp. has them cylindrical throughout, with rounded apex.

Description. Male: forewing length $5.5 \mathrm{~mm}(\mathrm{n}=1)$.

Head. Color yellowish brown (pinned specimen). Scape stout, elongate; pedicel enlarged in width, subequal to other flagellomeres in length, shorter than scape. Maxillary palps yellowish brown, 5-segmented, setose. Labial palps yellow, 3-segmented.

Thorax. Pterothorax yellowish brown; forewing light brown; faint band over cord; dark spots apically; forks I and V sessile; sectoral crossvein $(s)$ not aligned with $r-m$. Hind wing with forks I and V present. Legs yellowish brown. Tibial spur formula 0,2,2.

Abdomen. Segment IX annular, with short, triangular lateral processes present, broad basally, acute apically, projecting underneath dorsal lobe of tergum X; acrotergite present as two structures dorsolaterally (Figs. 15A-B). Preanal appendages short, rounded, bearing apical setae (Figs. 15A-B). Tergum X, in lateral view, divided into dorsal and ventral lobes; dorsal lobe modified into single structure, digitate, inflated preapically, subacute apically, same length as ventral lobe, with short setae (Figs. 15A-B); ventral lobe membranous, divided near apex by shallow, V-shaped incision, apex rounded (Fig. 15B). Inferior appendage 1-segmented, broad basally, setose (Figs. 15A, 15C); dorsal lobe smoothly projected, rounded, discrete (Figs. 15A); ventral lobe absent; distal lobe, as viewed laterally broad basally, tapering distally, bent dorsally at mid region, keeled ventrally, ventral margin distinctly angular, apex mesally curved and rounded (Figs. 15A, 15C); short and stout spine-like setae present on dorsal lobe and apical inner portion (Figs. 15A, 15C). Phallic apparatus bilaterally symmetrical, elongate, cylindrical, curved ventrally (Fig. 15D). One phallic spine present, straight (Fig. 15D). Phallotremal sclerite absent (Fig. 15D).

\section{Distribution. Guyana}

Material examined. Holotype (male): GUYANA, Essequebo [sic] R., Br. Guiana, July 1921, A. Busck coll [verbatim, no additional information given] (NMNH).

Etymology. From Latin licinus $=$ bent or turned upward. This species name refers to the distal lobe of inferior appendage bent dorsally.

\section{Concluding remarks}


762 This study raises the number of Oecetis in the Neotropics from 55 to 69 species. The new species 763 distributions are summarized in Fig. 16. It is noticeable that some of them are only known by 764 their holotype specimen since it was the only material available so far. Although this is not the 765 ideal situation, we choose to describe these new species instead of letting them sit in museum 766 collections for up to 20 years, as it can be seen in case of $O$. pertica, n. sp. Hopefully, in the 767 future, new information about their behavior or morphological variation can be provided with 768 additional specimens collection.

769 Even with our contribution on the Neotropical diversity of Oecetis, many other questions remain

770

771

772

773

774

775

776

777

778

779

780

781

782

783

784

785

786

787

788

789

790

791

792

793

794

795

796

797 unanswered. In this study, eight new species do not present diagnostic characters that allow us to place them in the already proposed taxonomic groups. This may be an indication that much of the diversity of the genus is still to be discovered, especially in Amazonia where many unexplored areas may harbor new species.

Another issue is the absence of phylogenetic hypothesis of Oecetis species. It has been suggested that the avara- and punctata-groups are closely related (Blahnik \& Holzenthal, 2014). Other than this, there is no further phylogenetic information on Oecetis species or groups of species. Since the phylogenetic relationships among species remain unclear, it is difficult to determine the placement of certain species to species group, for example. In this way, a phylogenetic study would be of much value to identify the character diversity present in Oecetis and how these characters are related to each other. Also, a phylogenetic hypothesis should properly evaluate the delimitation of the already proposed taxonomic groups (e.g., avara-, inconspicua-groups). Considering that some of the new species described here do not fit in any species group diagnosis, perhaps a re-delimitation of those groups is necessary. Since the genus currently contains more than 500 species divided in no more than a dozen species groups, a phylogenetic hypothesis becomes essential to a stable taxonomy with well circumscribed species groups.

\section{Acknowledgements}

We are very grateful to Dr. Roger Blahnik, Dr. Jane Hughes, and an anonymous reviewer for very insightful suggestions that improved the manuscript. We are grateful to Dr. Oliver S. Flint and Dr. Adolfo R. Calor for the generous loan of specimen loans. We appreciate the helpful suggestions on this manuscript of Adolfo R. Calor, Daniela M. Takiya, and Eduardo A. B. Almeida.

\section{References}

Angrisano EB., Sganga J V. 2009. Two new species of Trichoptera from Salto Encantado Provincial Park (Misiones Province, Argentina). Aquatic Insects 31:271-278. DOI: $10.1080 / 01650420903113729$. 
798

799

800

801

802

803

804

805

806

807

808

809

810

811

812

813

814

815

816

817

818

819

820

821

822

823

824

825

826

827

828

829

830

831

832

833

834

835

836

837

Blahnik RJ., Holzenthal RW. 2014. Review and redescription of species in the Oecetis avara group, with the description of 15 new species (Trichoptera, Leptoceridae). ZooKeys:1-83. DOI: $10.3897 /$ zookeys.376.6047.

Blahnik RJ., Holzenthal RW., Prather AL. 2007. The lactic acid method for clearing Trichoptera genitalia. In: Bueno-Soria J, Barba-Álvarez R, Armitage BJ eds. Proceedings of the XIIth International Symposium on Trichoptera. Columbus, Ohio: The Caddis Press, 9-14.

Botosaneanu L. 1977. Trichoptères (imagos) de Cuba, capturés par moi-meme en 1973 (Insecta, Trichoptera). Fragmenta Entomologica 13:231-284.

Bueno-Soria J. 1981. Estudios en insectos aquaticos de Mexico I. Trichoptera (Leptoceridae). Cinco nuevas especies de Oecetis McLachlan. Folia Entomológica Mexicana 49:103-120.

Calor A., Mariano R. 2012. UV Light Pan Traps for Collecting Aquatic Insects. Entomobrasilis 5:164-166.

Chen YE.unpublished. Revision of the Oecetis (Trichoptera: Leptoceridae) of the World. Clemson University, 1993.

Curtis J. 1834. Description of some hitherto nondescript British species of mayflies of anglers. The London and Edinburgh Philosophical Magazine and Journal of Science 3:120-125-218.

Dallwitz M., Paine T., Zurcher E. 1999. User's Guide to the DELTA Editor. Australia: CSIRO Division of Entomology.

Denning DG. 1947. New Trichoptera from Puerto Rico. Annals of the Entomological Society of America 40:656-661.

Flint OS, Jr. 1974. The Trichoptera of Surinam. Studies of Neotropical caddisflies, XV. Studies on the Fauna of Suriname and other Guyanas 14:1-151.

Flint OS, Jr. 1981. Studies of Neotropical caddisflies, XXVIII: the Trichoptera of the Río Limón basin, Venezuela. Smithsonian Contributions to Zoology 330:1-61.

Flint OS, Jr. 1991. Studies of Neotropical Caddisflies, XLIV: On a collection from Ilha de Maraca, Brazil. Acta Amazonica 21:63-83.

Hagen HA. 1861. Synopsis of the Neuroptera of North America with a list of the South American species. Smithsonian Miscellaneous Collections 4:1-347.

Henriques-Oliveira A., Dumas L., Nessimian J. 2014. Three new species and new distributional records of Oecetis McLachlan 1877 (Trichoptera: Leptoceridae: Leptocerinae) from Brazil. Zootaxa 3753:273-282.

Holzenthal RW., Calor AR. 2017. Catalog of the Neotropical Trichoptera (Caddisflies). ZooKeys 654:1-566. DOI: 10.3897/zookeys.654.9516.

Lee SJ., Hwang JH., Bae YJ. 2012. The caddisfly genus Oecetis McLachlan (Trichoptera: Leptoceridae) in Korea. Entomological Research 42:271-280. DOI: 10.1111/j.17485967.2012.00466.x.

Malicky H. 2005. Beiträge zur Kenntnis asiatischer Oecetis ( Trichoptera, Leptoceridae ). Linzer Biologische Beiträge 37:605-669.

McLachlan R. 1877. A monographic revision and synopsis of the Trichoptera of the European fauna (1874-1880). London: John van Voorst. 
838 Navás L. 1924. Insectos de la Amériea Central. Brotéria, Série Zoológica 21:55-86.

839 Neboiss A. 1989. The Oecetis reticulata species-group from the South-West Pacific area 840 (Trichoptera: Leptoceridae). Bijdragen tot de Dierkunde 59:191-202.

841 Quinteiro FB., Calor AR. 2012. A new species of Oecetis McLachlan, 1877 (Trichoptera:

842 Leptoceridae) from Southeast Brazil: Validation of an unpublished species. Zootaxa $843 \quad 3442: 53-61$.

844 Quinteiro F., Calor A. 2015. A Review of the genus Oecetis (Trichoptera: Leptoceridae) in the 845 Northeastern Region of Brazil with the Description of 5 New Species. PloS one 846 10:e0127357. DOI: 10.1371/journal.pone.0127357.

847 Rueda-Martín P., Gibon FM., Molina CI. 2011. The genus Oecetis McLachlan in Bolivia and Northwestern Argentina (Trichoptera: Leptoceridae), with new species and identification key for males of Oecetis species from Mexico, Central and South America. Zootaxa 38:1938.

Schmid F. 1998. The Insects and Arachnids of Canada. Part 7.Genera of the Trichoptera of Canada and Adjoining or Adjacent United States. NRC Research Press. 
Figure 1

Figure 1. Male genitalia of Oecetis acuticlasper n. sp.

Oecetis acuticlasper n. sp., Quinteiro \& Holzenthal, male holotype. A-forewing. B-hindwing.

C-genitalia, lateral view. D-genitalia, dorsal view. E-genitalia, ventral view. F-phallic apparatus, lateral view. G-phallic apparatus, dorsal view.
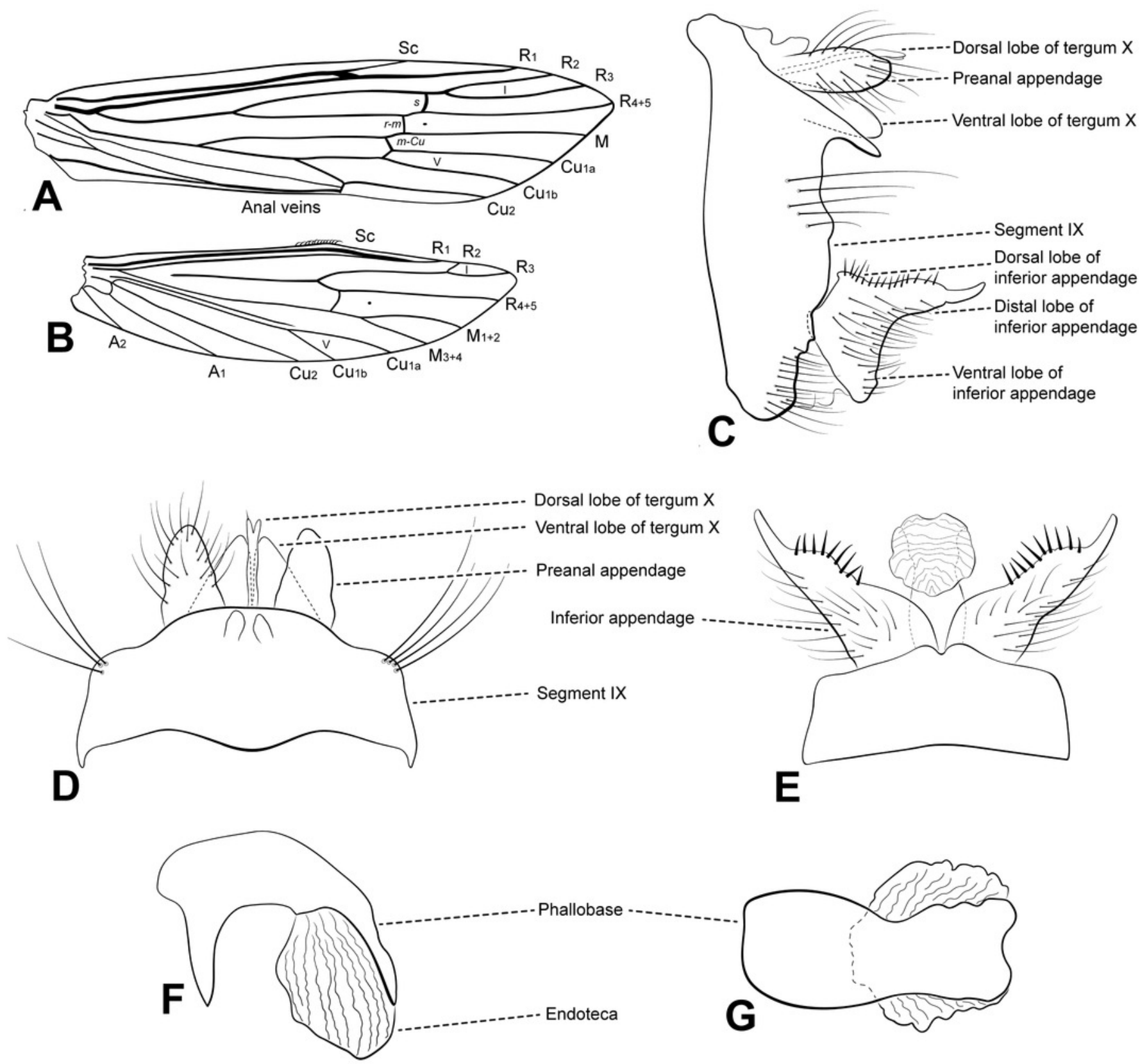


\section{Figure 2}

Figure 2. Male genitalia of Oecetis flinti n. sp.

Oecetis flinti n. sp., Quinteiro \& Holzenthal, male holotype. A-forewing. B-hindwing. C-genitalia, lateral view. D-genitalia, dorsal view. E-genitalia, ventral view. F-phallic apparatus, lateral view. G-phallic apparatus, dorsal view. 

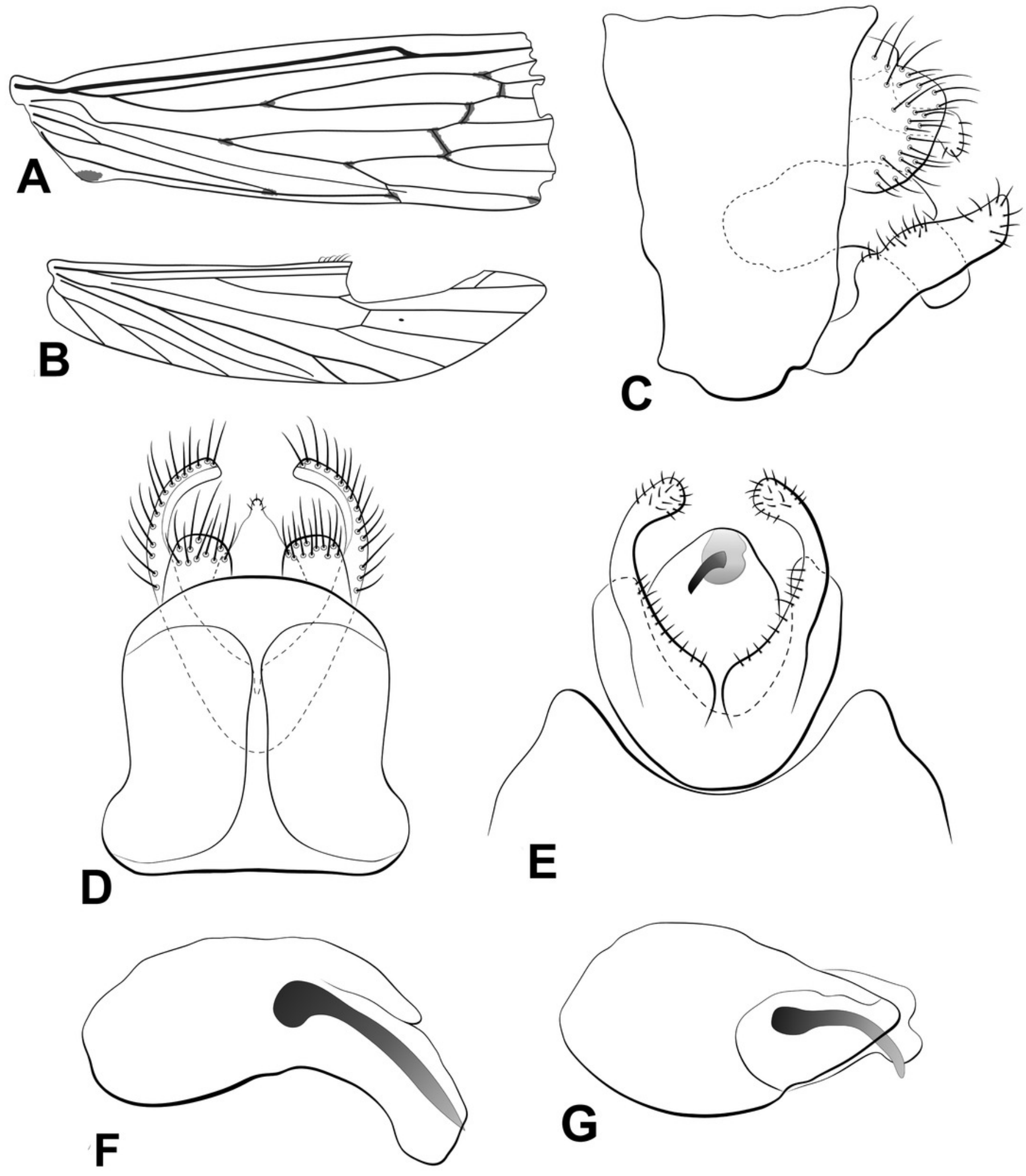


\section{Figure 3}

Figure 3. Male genitalia of Oecetis carinata n. sp.

Oecetis carinata n. sp., Quinteiro \& Holzenthal, male holotype. A-forewing. B-hindwing.

C-genitalia, lateral view. D-genitalia, dorsal view. E-genitalia, ventral view. F-phallic apparatus, lateral view. G-phallic apparatus, dorsal view. 

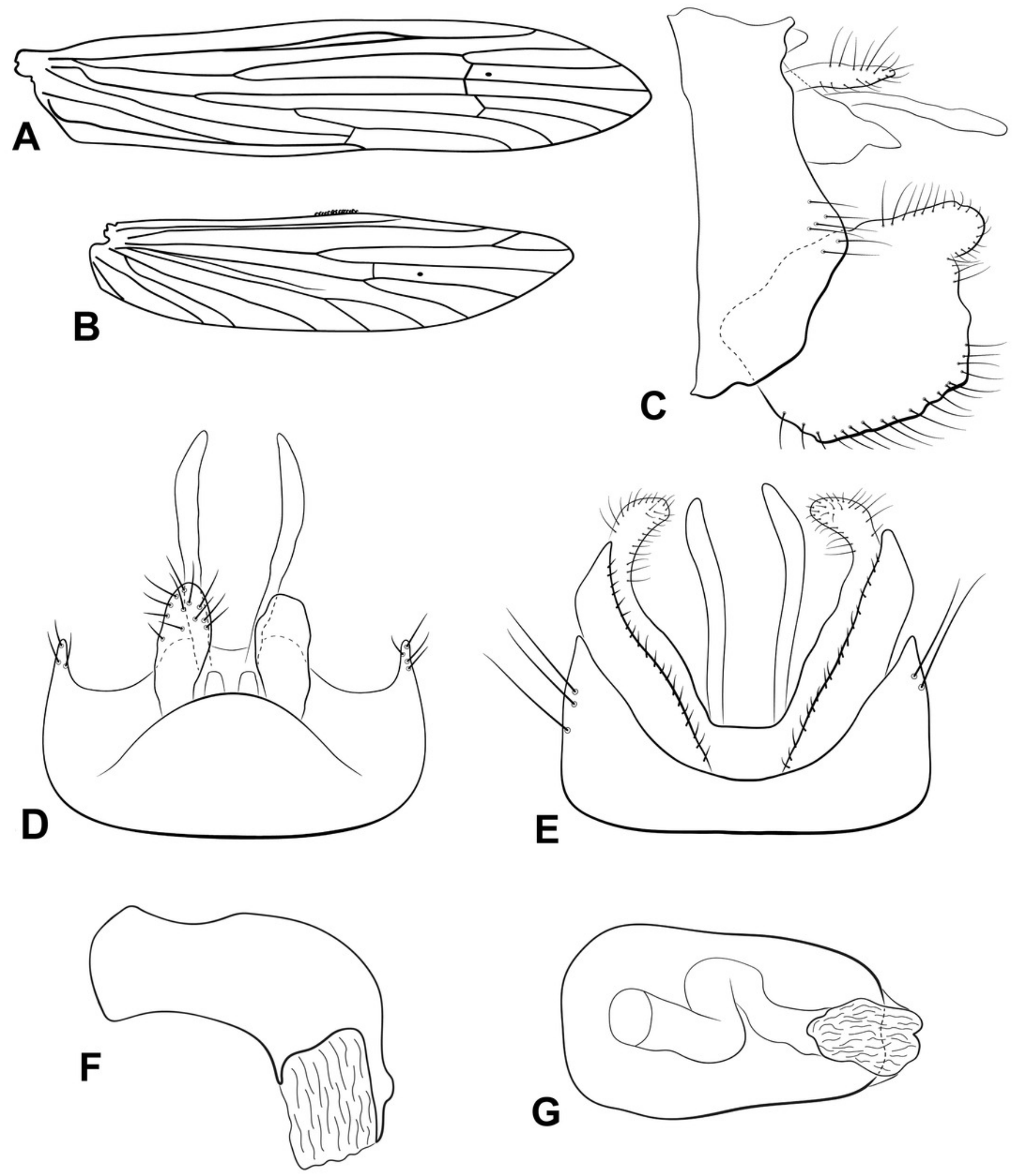
Figure 4

Figure 4. Male genitalia of Oecetis cassicoleata n. sp.

Oecetis cassicoleata n. sp., Quinteiro \& Holzenthal, male holotype. A-forewing. B-hindwing. C-genitalia, lateral view. D-genitalia, dorsal view. E-phallic apparatus, lateral view. F-phallic apparatus, dorsal view.
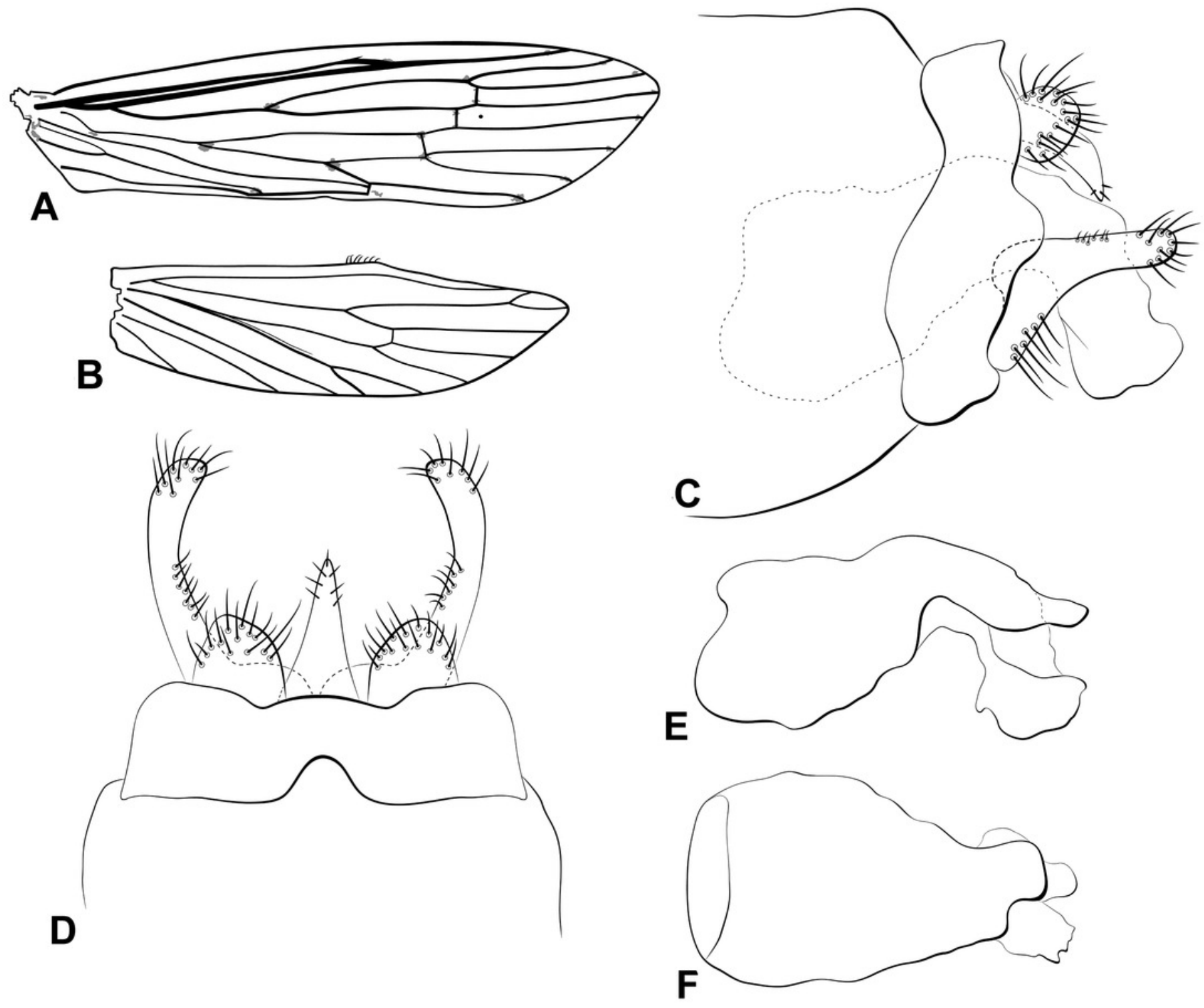


\section{Figure 5}

Figure 5. Male genitalia of Oecetis bidigitata n. sp.

Oecetis bidigitata n. sp., Quinteiro \& Holzenthal, male holotype. A-forewing. B-hindwing. C-genitalia, lateral view. D-genitalia, dorsal view. E-inferior appendage, ventral view. F-phallic apparatus, lateral view. G-phallic apparatus, caudal view. H-phallic apparatus, dorsal view. 

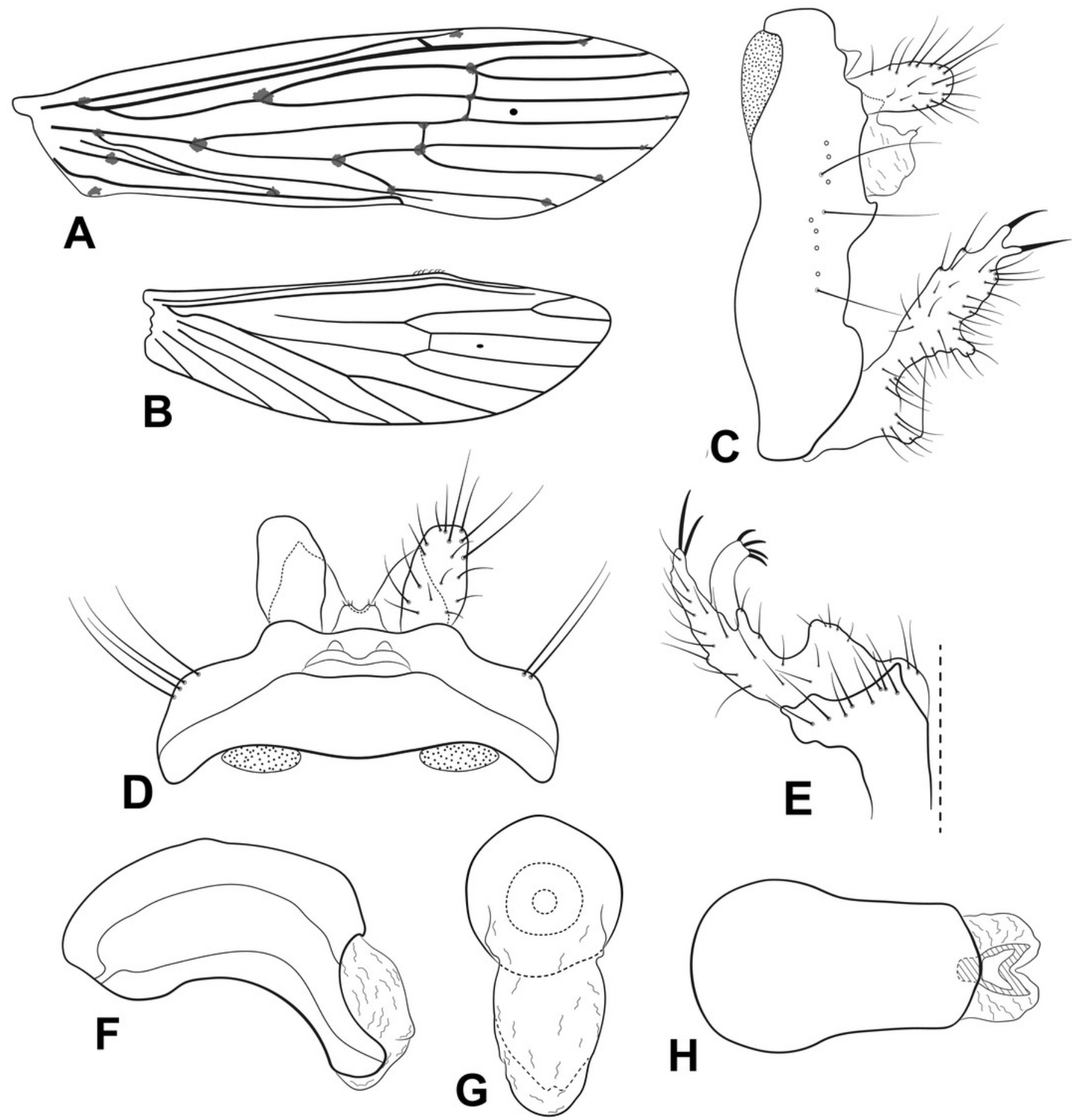
Figure 6

Figure 6. Male genitalia of Oecetis quasipunctata n. sp.

Oecetis quasipunctata n. sp., Quinteiro \& Holzenthal, male holotype. A-forewing. B-hindwing.

C-genitalia, lateral view. D-genitalia, dorsal view. E-inferior appendage, ventral view.

F-phallic apparatus, lateral view. G-phallic apparatus, caudal view. H-phallic apparatus, dorsal view.
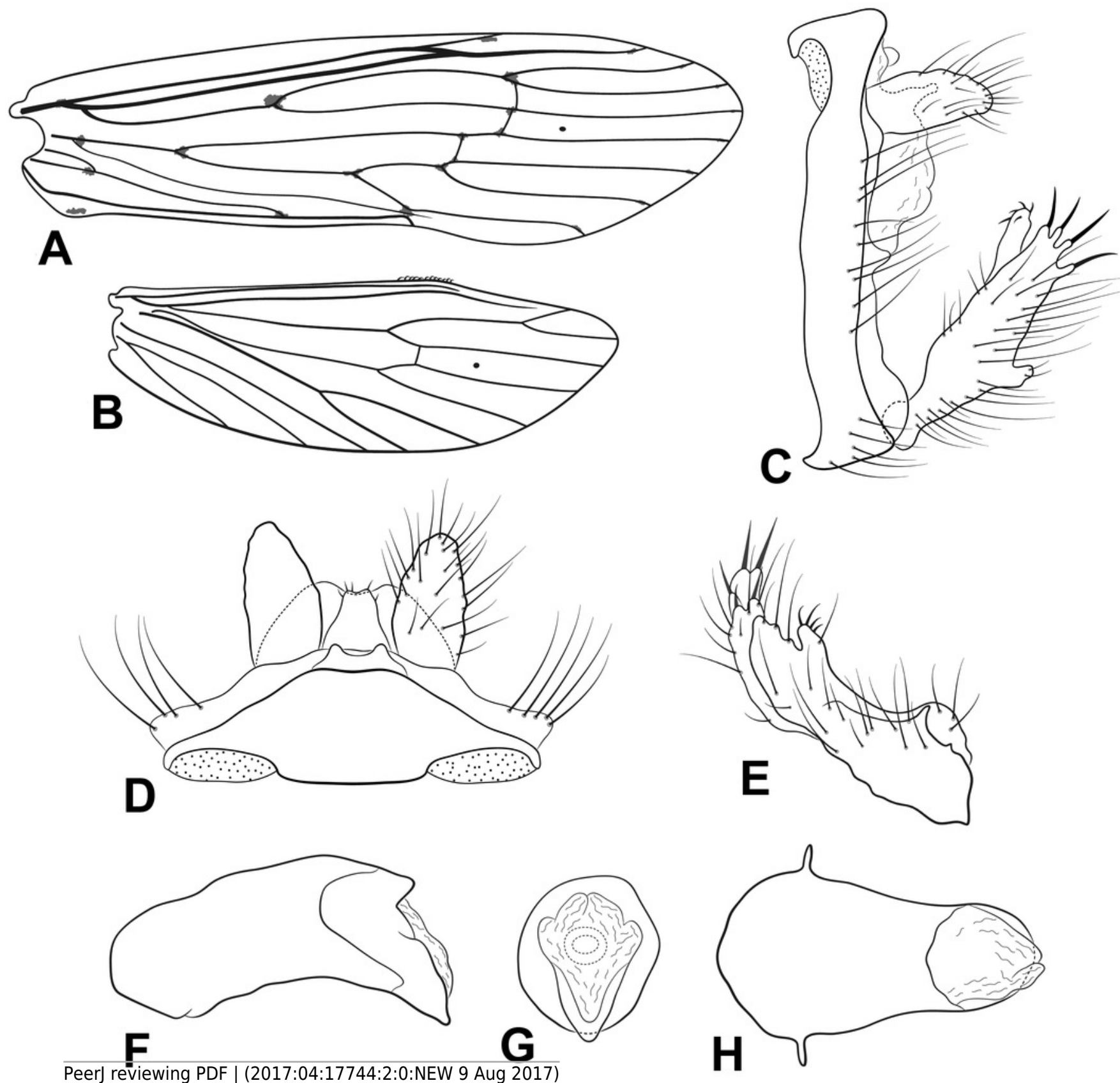


\section{Figure 7}

Figure 7. Male genitalia of Oecetis punctata (Navás, 1924).

Oecetis punctata (Navás, 1924); specimen label: Colombia, Magdalena, Municipio de Santa

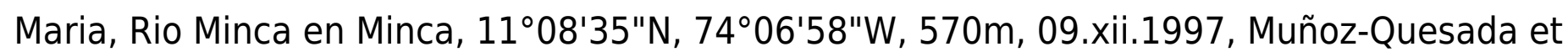
al. A-forewing. B-hindwing. C-genitalia, lateral view. D-genitalia, dorsal view. E-inferior appendage, ventral view. F-phallic apparatus, lateral view. G-phallic apparatus, dorsal view. 

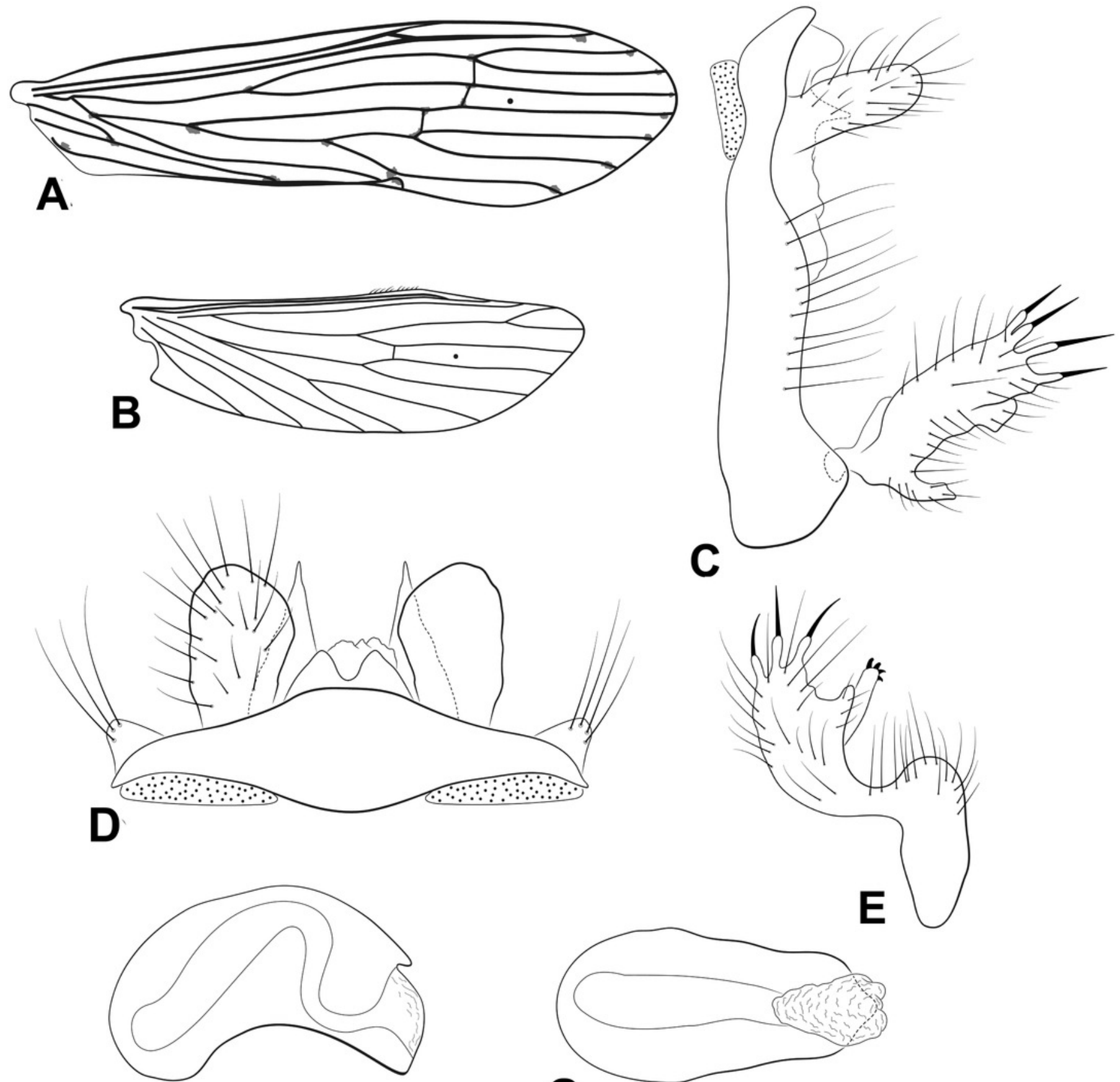

F

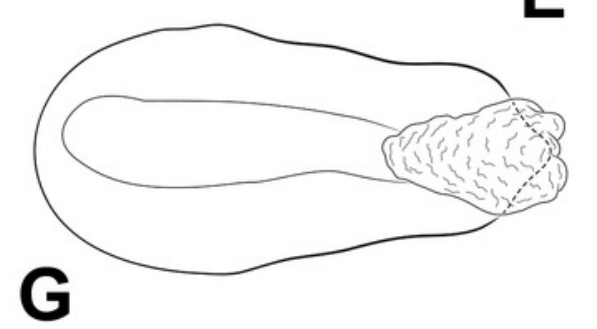




\section{Figure 8}

Figure 8. Male genitalia of Oecetis calori n. sp.

Oecetis calori n. sp., Quinteiro \& Holzenthal, male holotype. A-forewing. B-hindwing.

C-genitalia, lateral view. D-genitalia, dorsal view. E-inferior appendage, ventral view.

F-phallic apparatus, lateral view. G-phallic apparatus, caudal view. H-phallic apparatus, dorsal view. Black arrowheads indicate tergum $\mathrm{X}$ lobules. 

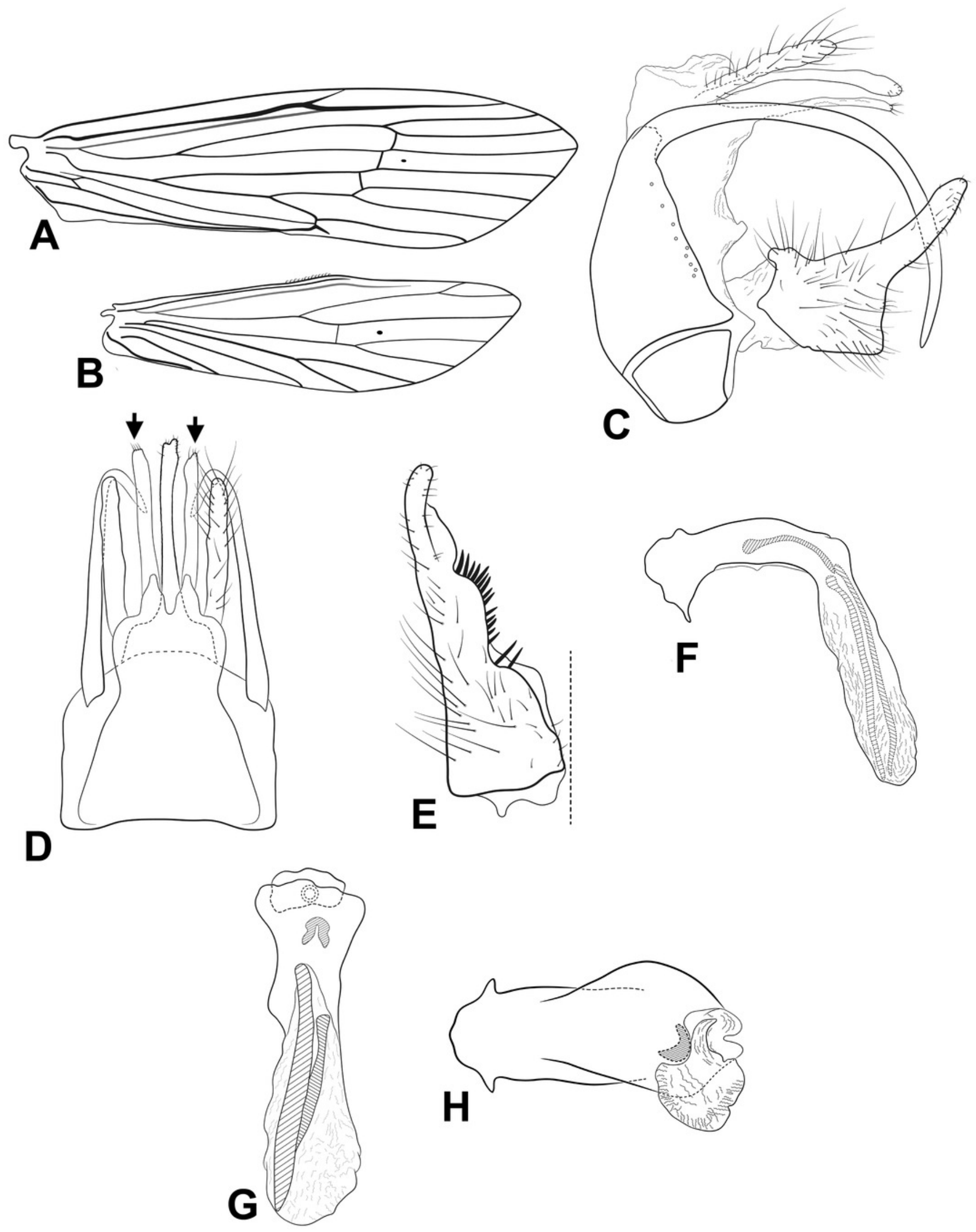
Figure 9

Figure 9. Male genitalia of Oecetis hastapulla n. sp.

Oecetis hastapulla n. sp., Quinteiro \& Holzenthal, male holotype. A-forewing. B-hindwing. C-genitalia, lateral view. D-genitalia, dorsal view. E-inferior appendage, ventral view. F-phallic apparatus, lateral view. G-phallic apparatus, caudal view. H-phallic apparatus, dorsal view.
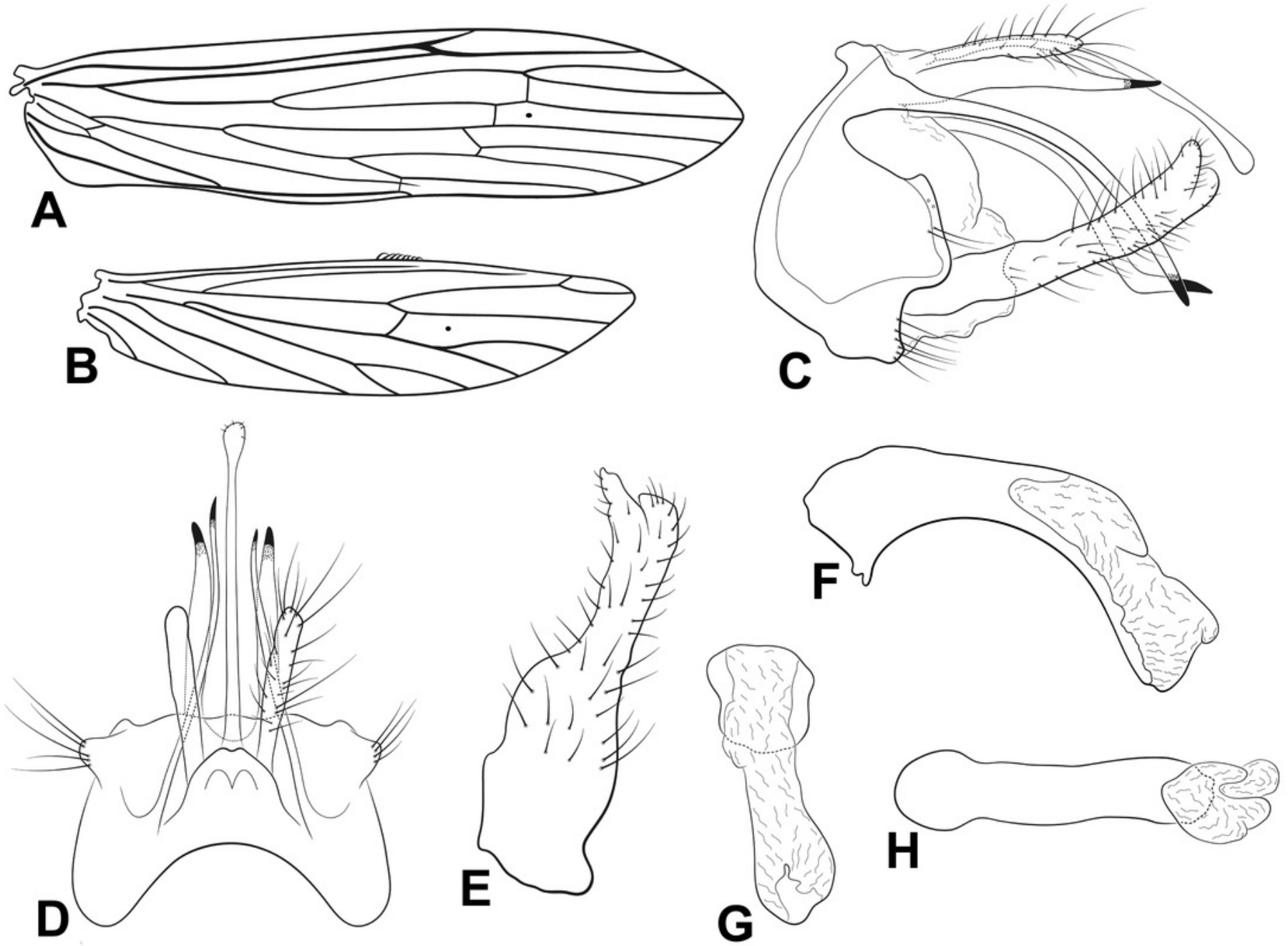


\section{Figure 10}

Figure 10. Male genitalia of Oecetis plenuspinosa n. sp.

Oecetis plenuspinosa n. sp., Quinteiro \& Holzenthal, male holotype. A-abdominal terga V,VI, VII, VIII, dorsal view. B-abdominal tergum VI texture, dorsal view. C- abdominal tergum VIII texture, dorsal view. D-genitalia, lateral view. E-genitalia, dorsal view. F-inferior appendage, ventral view. G-phallic apparatus, lateral view. 

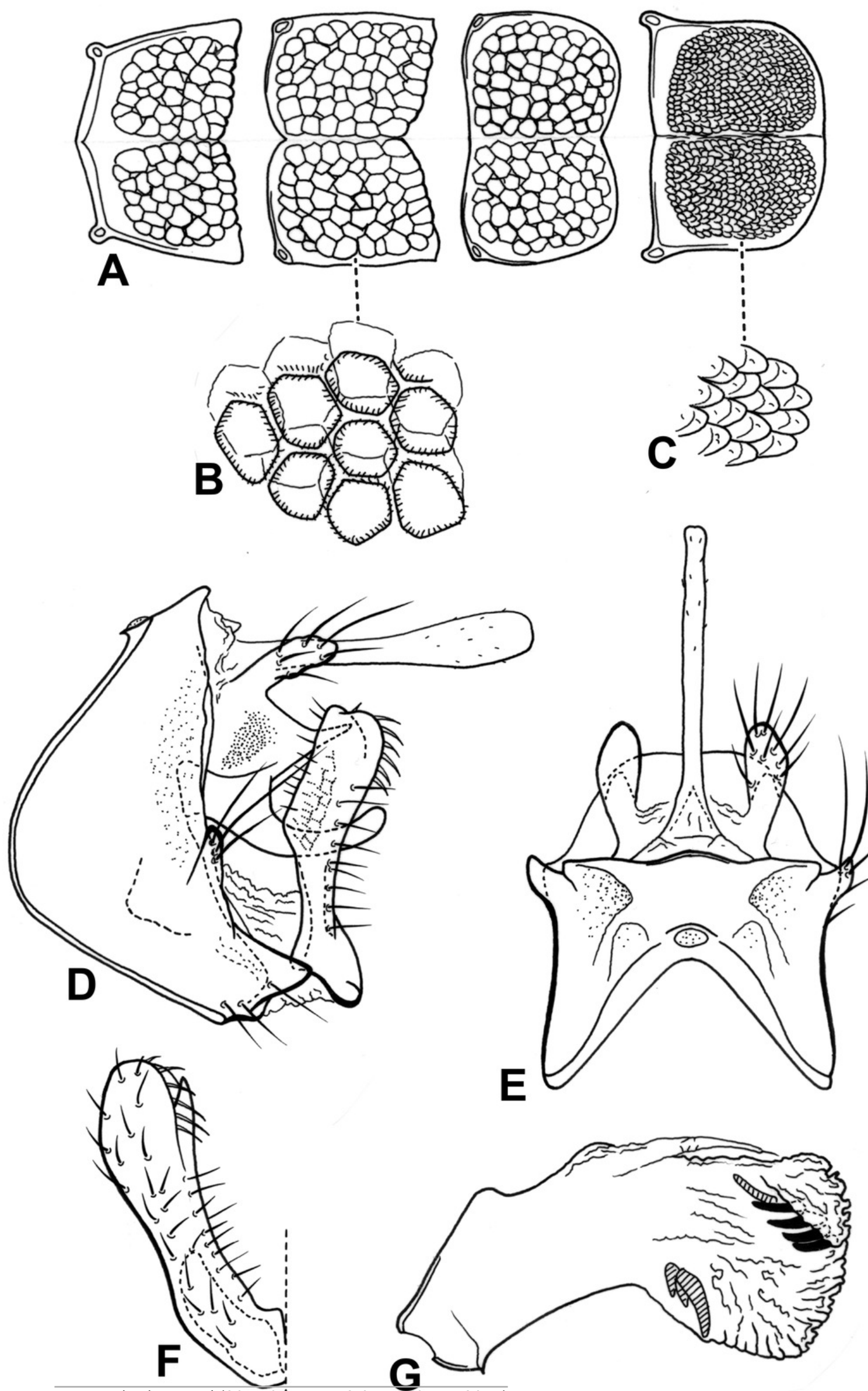


\section{Figure 11}

Figure 11. Male genitalia of Oecetis machaera n. sp.

Oecetis machaera n. sp., Quinteiro \& Holzenthal, male holotype. A-genitalia, lateral view. B-genitalia, dorsal view. C-genitalia, ventral view. D-phallic apparatus, lateral view. 

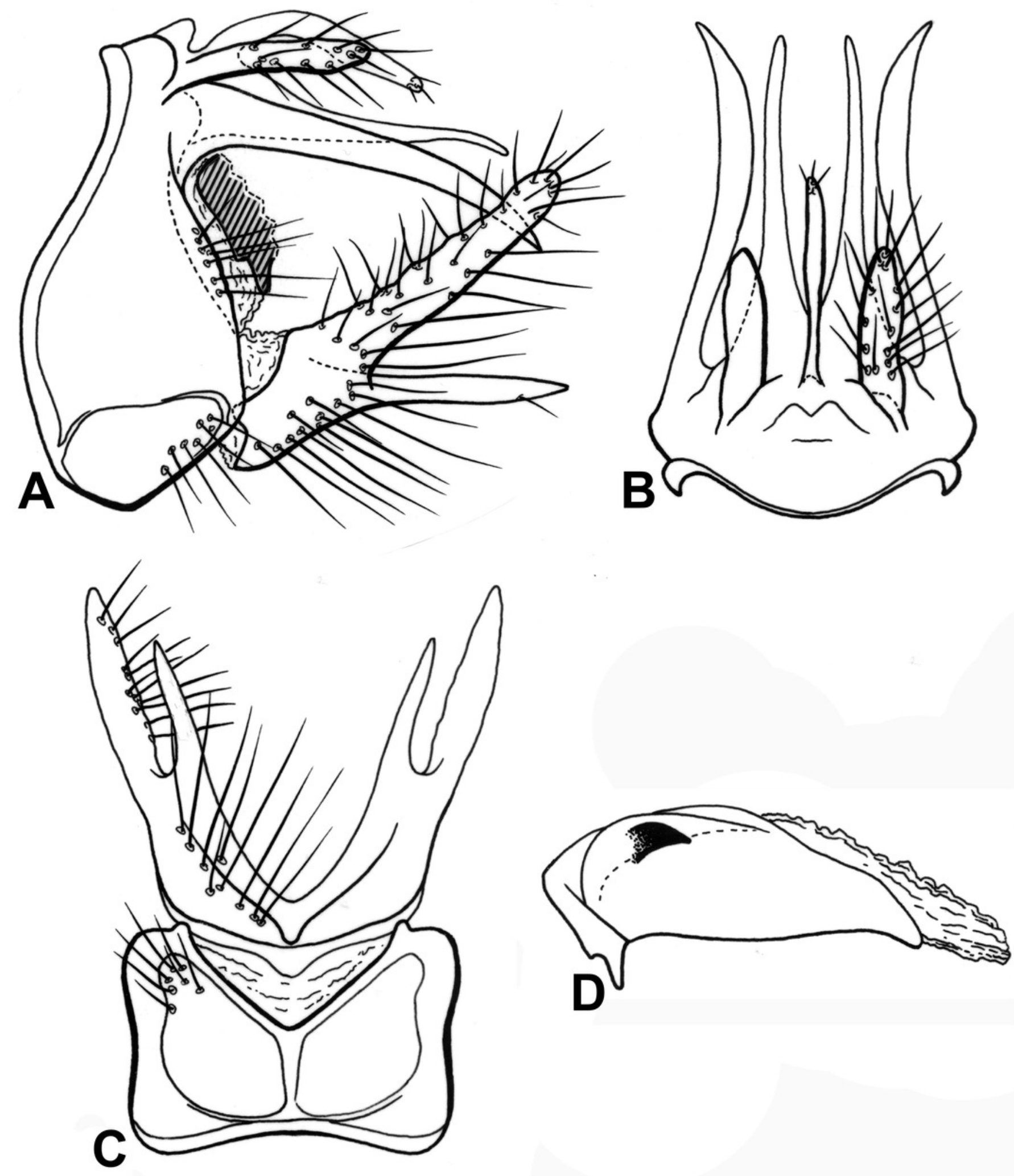
Figure 12

Figure 12. Male genitalia of Oecetis blahniki n. sp.

Oecetis blahniki n. sp., Quinteiro \& Holzenthal, male holotype. A-genitalia, lateral view. B-genitalia, dorsal view. C-inferior appendage, ventral view. D-phallic apparatus, lateral view.

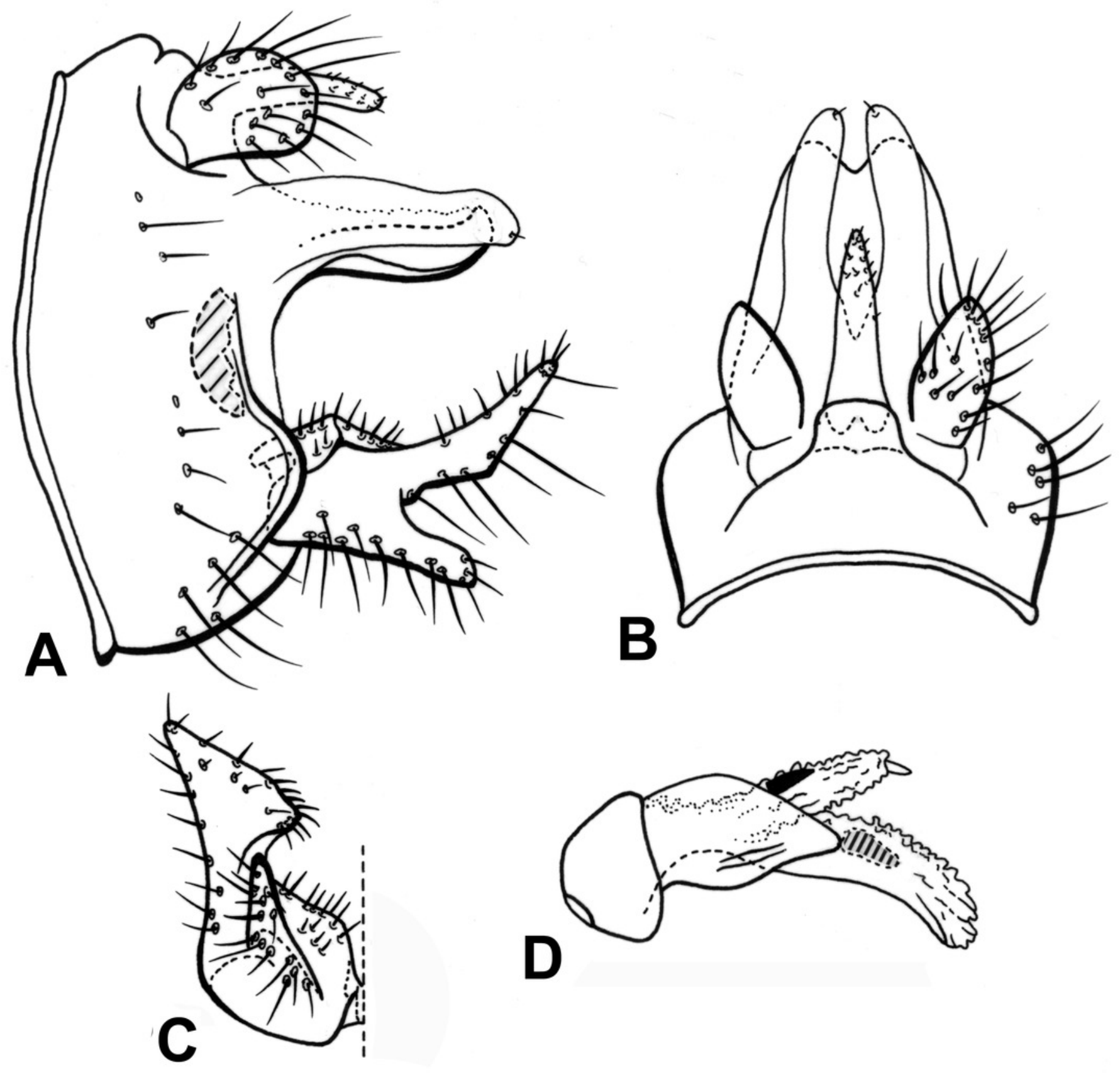


Figure 13

Figure 13. Male genitalia of Oecetis gibbosa n. sp.

Oecetis gibbosa n. sp., Quinteiro \& Holzenthal, male holotype. A-genitalia, lateral view. A'-dorsal lobe of inferior appendage, caudal view. B-genitalia, dorsal view. C-inferior appendage, ventral view. D-phallic apparatus, lateral view.

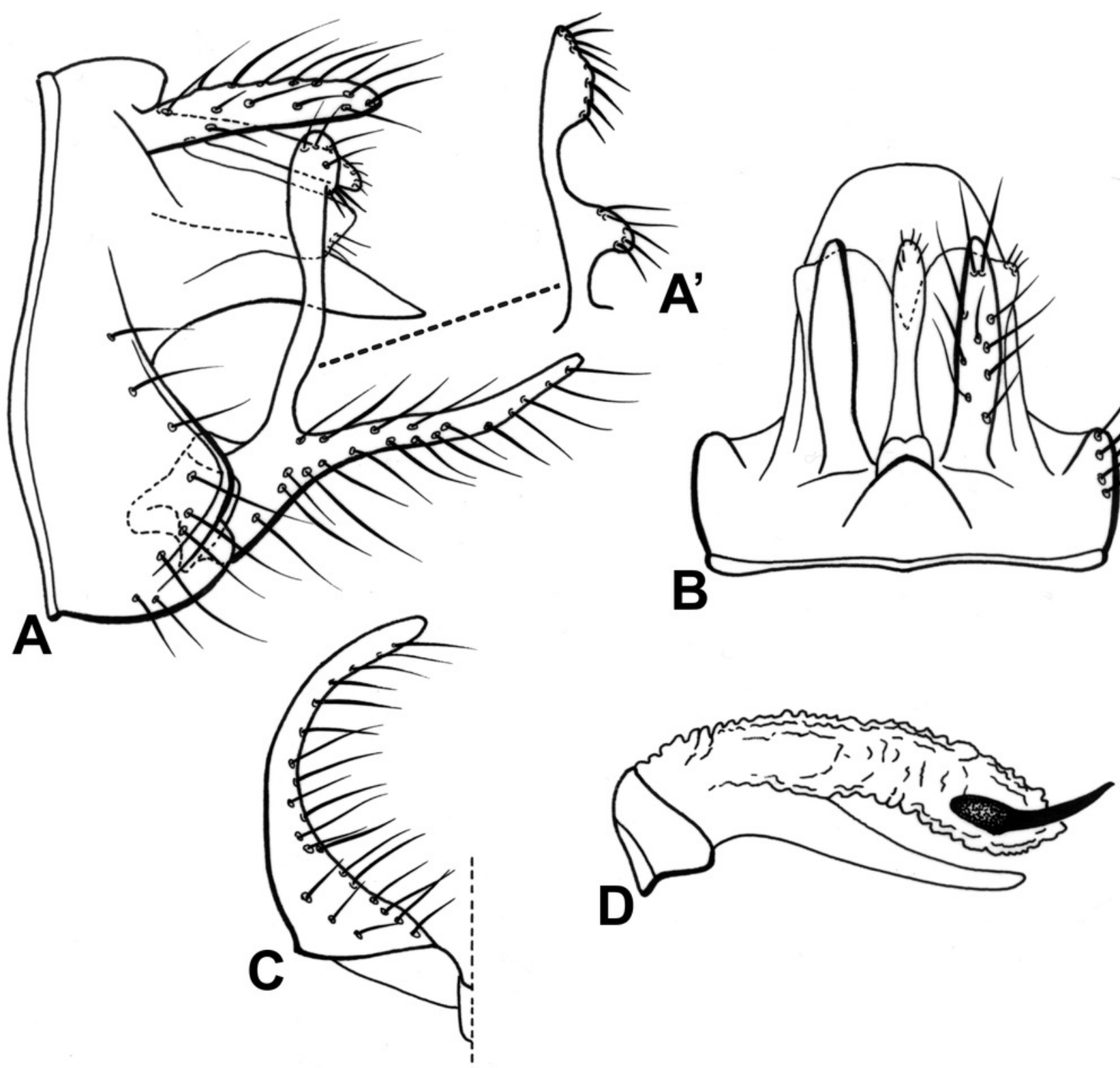


Figure 14

Figure 14. Male genitalia of Oecetis pertica n. sp.

Oecetis pertica n. sp., Quinteiro \& Holzenthal, male holotype. A-genitalia, lateral view.

B-genitalia, dorsal view. C-inferior appendage, ventral view. D-phallic apparatus, lateral view.

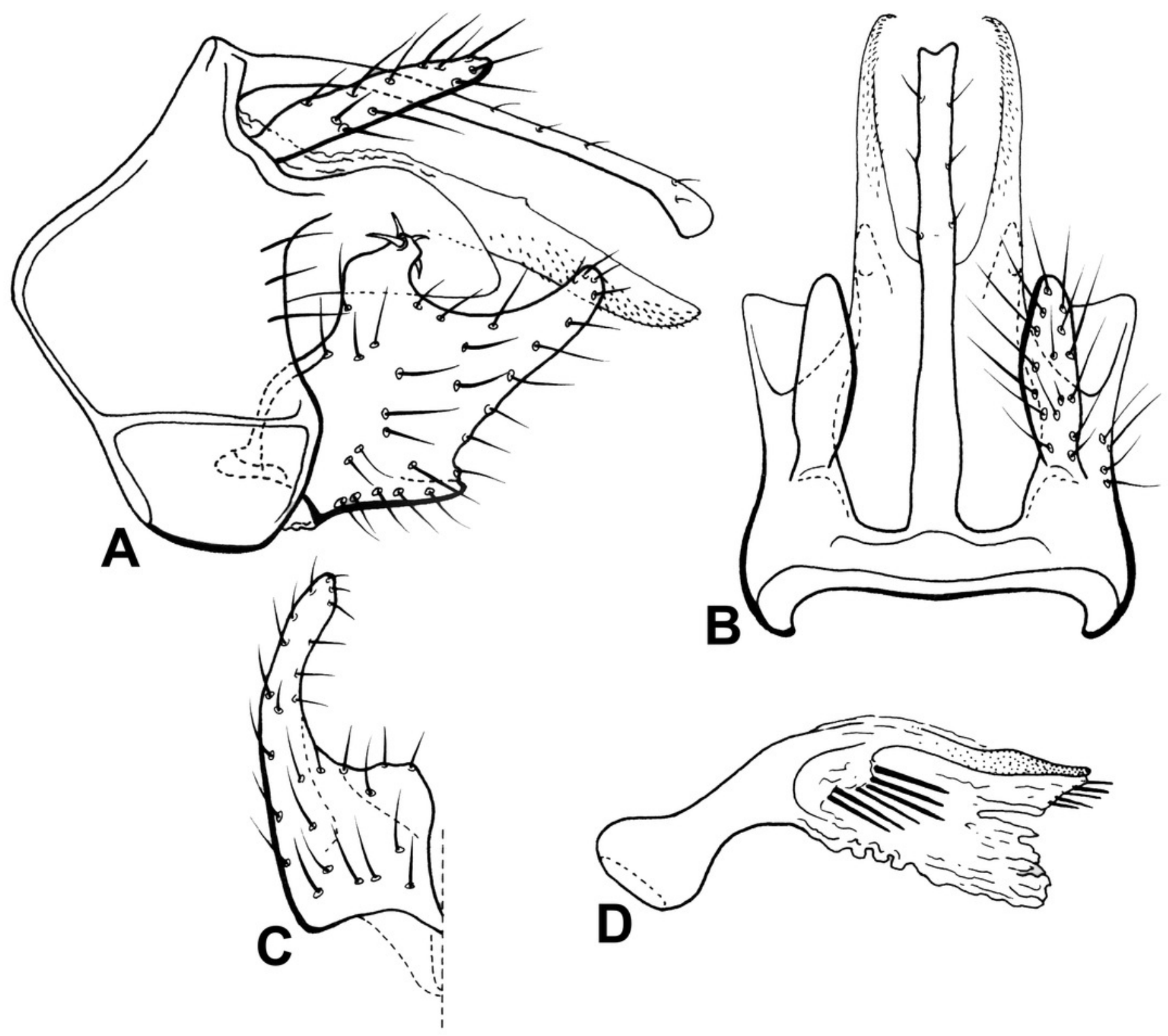




\section{Figure 15}

Figure 15. Male genitalia of Oecetis licina n. sp.

Oecetis licina n. sp., Quinteiro \& Holzenthal, male holotype. A-genitalia, lateral view.

B-genitalia, dorsal view. C-inferior appendage, ventral view. D-phallic apparatus, lateral view. 


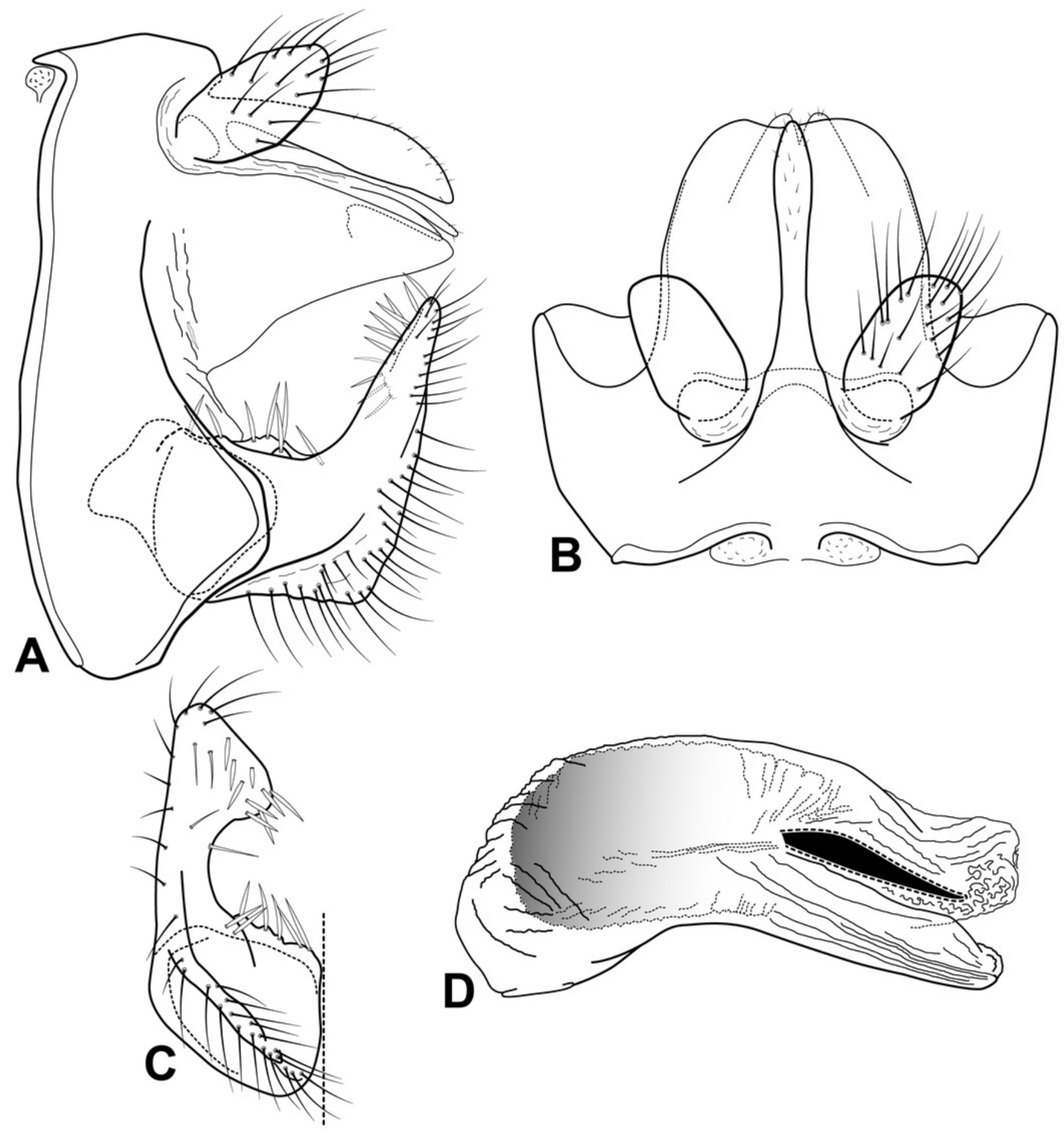


Figure 16

Figure 16. Distribution of the 14 new species of Oecetis.

Distribution map of the 14 new species of Oecetis based on the specimens presented on material examined sections.
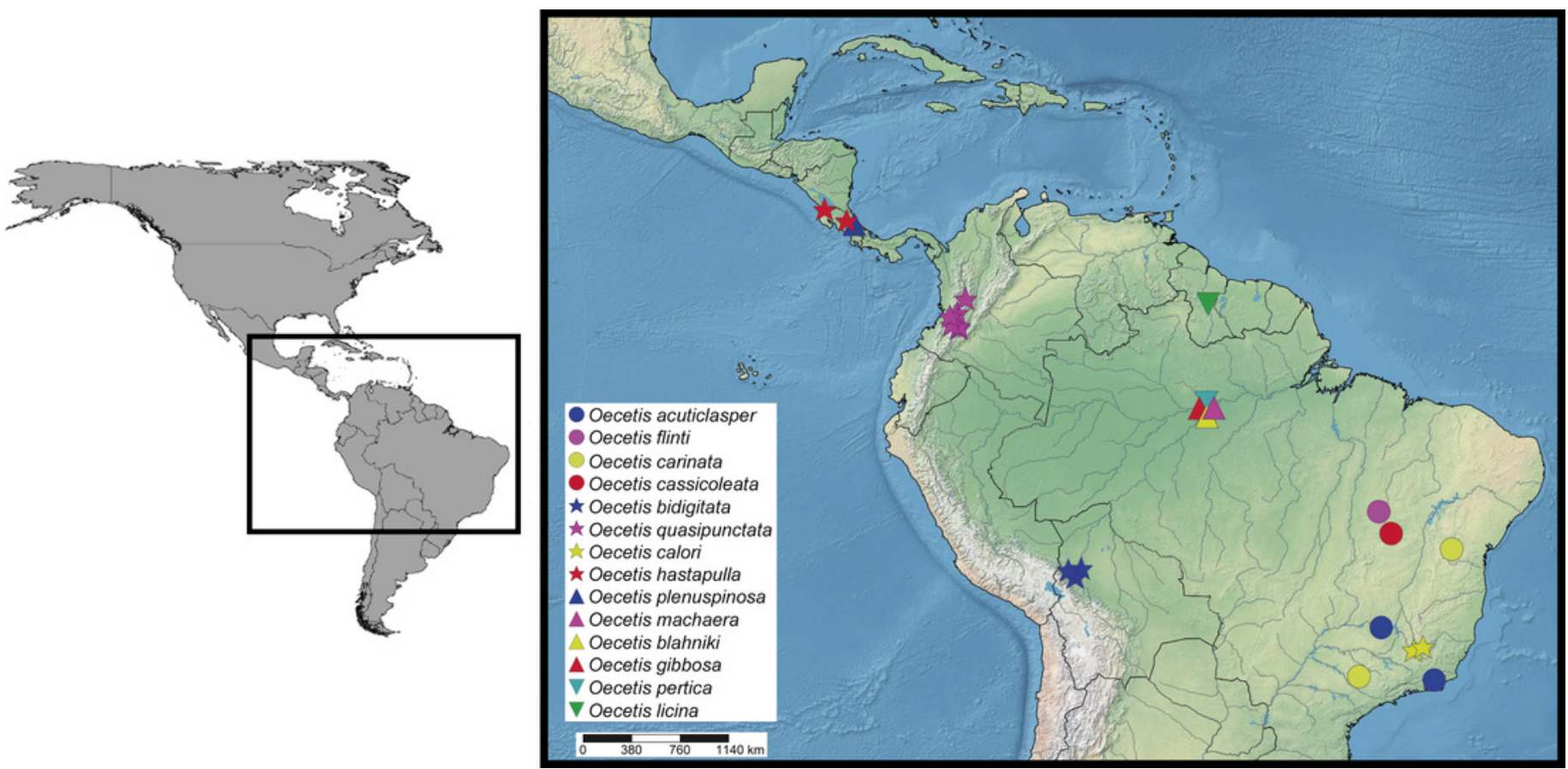